\title{
Influence of Stress Path on Stress Memory and Stress Fracturing in Brittle Rocks
}

\begin{tabular}{|r|l|}
\hline Journal: & Canadian Geotechnical Journal \\
\hline Manuscript ID & cgj-2018-0291.R1 \\
\hline Manuscript Type: & Article \\
\hline Author: & 21-Jul-2018 \\
\hline Complete List of Authors: & $\begin{array}{l}\text { Bahrani, Navid; Dalhousie University, Civil and Resource Engineering } \\
\text { Valley, Benoît; University of Neuchâtel, Centre for Hydrogeology and } \\
\text { Geothermics } \\
\text { Kaiser, Peter; Laurentian University, Bharti School of Engineering }\end{array}$ \\
\hline Keyword: & stress path, stress fracturing, core damage, stress memory, Kaiser Effect \\
\hline $\begin{array}{r}\text { Is the invited manuscript for } \\
\text { consideration in a Special } \\
\text { Issue? : }\end{array}$ & Not applicable (regular submission) \\
\hline &
\end{tabular}

\section{SCHOLARONE ${ }^{m}$ Manuscripts}




\section{Influence of Stress Path on Stress Memory and Stress Fracturing in Brittle Rocks}

Navid Bahrani' ${ }^{1}$, Benoît Valley², Peter K. Kaiser ${ }^{3}$

${ }^{1}$ Department of Civil and Resource Engineering, Dalhousie University, Halifax, NS, Canada

${ }^{2}$ Centre for Hydrogeology and Geothermics, University of Neuchâtel, Neuchâtel, Switzerland

${ }^{3}$ Bharti School of Engineering, Laurentian University, Sudbury, ON, Canada

pg. 1 


\section{ABSTRACT}

A two-dimensional numerical model based on the Distinct Element Method, previously calibrated to the laboratory properties of undamaged and damaged Lac du Bonnet (LdB) granite, was used to investigate the influence of stress path on the development of stress memory and stress fracturing in brittle rocks. Various cycles of loading and unloading, similar to those imposed during Kaiser Effect tests, were first applied to undamaged numerical specimens of LdB granite. The results of Kaiser Effect test simulations were found to be consistent with those of published laboratory and numerical investigations. Further simulations were conducted to investigate the influence of stress path resulting from the excavation of a tunnel on the depth of stress fracturing around the excavation boundary. For this purpose, the stress paths at points on and near the tunnel wall, obtained from a continuum finite element model, were applied to the calibrated numerical specimen. It was found that the amount of damage in the numerical specimens decreases rapidly with increasing distance from the excavation wall. The findings of this research shed some light on the influence of stress path and grain-scale heterogeneity on stress memory in brittle rocks and stress fracturing around underground openings.

Keywords: Stress path, stress fracturing, core damage, stress memory, Kaiser Effect

pg. 2 


\section{INTRODUCTION}

It is well documented from laboratory experiments using strain monitoring and acoustic emission records that a brittle rock gets progressively damaged due to initiation and propagation of microcracks, and eventually fails by crack coalescence when its peak strength is reached (Griffith 1924; Martin and Chandler 1994; Martin 1997). This is due to the fact that brittle rocks are made of heterogeneous mineral assemblies. The presence of heterogeneities results in the generation of internal stress variations in magnitude and orientation and, in low compressive stress fields, leads to tensile stresses that promote the generation of extension cracks before the peak strength is reached.

Despite rapid developments in numerical modeling tools and enhanced computing power, a realistic simulation of the progressive failure of brittle rocks remains a challenge. Numerical simulations based on continuum methods do not provide a realistic representation of brittle rock fracturing process, as they ignore the role of grain-scale heterogeneities on the development of tensile cracks. On the other hand, numerical simulations based on discontinuum methods such as recently developed grain-based modeling approaches in PFC (Bahrani et al. 2014) and UDEC (Gao et al. 2016), although respecting the grain-scale heterogeneities and inter- and intra-grain cracking, are usually limited to the simulation of laboratory scale tests with simple stress paths. In the field, rock fracturing and failure processes are the results of complex stress paths during rock excavations (Kaiser et al. 2000; Eberhardt 2001; Diederichs et al. 2004). Such complex stress paths occur in situations involving progressive excavation of a volume of rock at various scales, such as the stress path of a point in the vicinity of the wall of an advancing tunnel (Martin 1997), or inside the core during drilling of a borehole in highly stressed grounds (Lim and Martin 2010; Lim et al. 2013; Bahrani et al. 2015). Cyclic loading of laboratory specimens also involves

pg. 3 
complex stress paths, e.g., during Kaiser effect tests used for the determination of in situ stress magnitudes (Lavrov 2003).

As discussed by Lan et al. (2010) and Valley et al. (2010), grain-scale heterogeneity in an intact brittle rock can be divided into three types: 1. Grain geometric heterogeneity resulting from different shapes and sizes of grains; 2 . Grain property heterogeneity resulting from stiffness and strength contrast between different mineral grains; and 3. Grain contact heterogeneity due to varying grain boundary lengths, orientations and properties.

Numerical simulations of brittle rock specimens by Diederichs (1999), Lan et al. (2010), Valley et al. (2010), and Bahrani et al. (2015) provide insights into the influence of grain-scale heterogeneity on the generation of internal tensile stresses under an overall compressive stress field. It is concluded from the results of these investigations that the geometric variations in the shape of rock grains as well as the stiffness contrast between them are the main factors in generating tensile stresses in brittle rocks, which leads to its progressive failure during compressive loading.

The stress paths of the laboratory tests to obtain the unconfined and confined rock strengths are relatively simple and involve monotonic increases in the axial and/or lateral stresses. However, the stress paths inside a core during drilling and near the wall of an advancing tunnel can be more complex, involving stress increase, decrease, and rotation in the region close to the excavation (Martin 1993). Factors influencing the stress path, amongst others, are the ratio of far field principal stresses, and the shape and direction of an excavation relative to the orientation of the in situ stress tensor. If the ratio of the induced stress to the rock strength is high enough, this excavation-induced stress change may lead first to rock damage with crack initiation, propagation, and coalescence leading to failure of the rock; e.g., core damage and disking in the

pg. 4 
case of drilling a core (Lim and Martin 2010; Lim et al. 2013) and spalling in the form of a vshaped notch in the case of an advancing tunnel (Martin 1993, 1997).

Fig. 1 compares the stress path of a point inside a core during drilling from a vertical borehole parallel to the direction of minimum principal stress $\left(\sigma_{3}\right)$, and the stress path of a point at the wall of a horizontal tunnel excavated parallel to the direction of intermediate principal stress $\left(\sigma_{2}\right)$. These stress paths were obtained from elastic three-dimensional (3D) continuum models (Read et al. 1998, Bahrani et al. 2015) with properties of the undamaged Lac de Bonnet (LdB) granite and in situ stresses representative for the 420-level of the AECL's Underground Research Laboratory (URL), Manitoba, Canada (Martin 1997).

In the case of core drilling, the magnitude of $\sigma_{1}$ inside the core increases as the magnitude of $\sigma_{3}$ decreases, until the stress path reaches the average tensile strength of the undamaged LdB granite. Then, the magnitudes of $\sigma_{1}$ and $\sigma_{3}$ are gradually reduced to a "zero stress" state. The cores retrieved from vertical boreholes exhibited various levels of damage (Lim and Martin 2010; Martin and Stimpson 1994; Eberhardt et al. 1999). An example of drilling-induced core disking is shown in Fig. 1c. In the case of tunnel wall, similar to the coring stress path, $\sigma_{1}$ increases and $\sigma_{3}$ decreases until the stress path gets very close to the failure envelope in the tension zone. From this point, the stress path undergoes a cycle of loading and unloading, and then it increases to a maximum stress of $169 \mathrm{MPa}$, which is less than the average unconfined compressive strength (UCS = $213 \mathrm{MPa}$ ) of undamaged LdB granite (Martin and Stimpson 1994; Eberhardt et al. 1999). Fig. 1b shows the v-shaped notch failure formed around the mine-by experiment near the location of the maximum tangential stress.

Despite many advances in numerical modeling over the last two decades, realistic simulations of core damage leading to core disking ( $\mathrm{Li}$ and Schmitt 1997, 1998; Corthesy and Leite 2008;

pg. 5 
Bahrani et al. 2015) and stress fracturing near excavation boundaries leading to v-shaped notch failure (Hadjiabdolmajid et al. 2002; Potyondy and Cundall 2004; Cai and Kaiser 2013; Vazaios et al. 2018) in brittle rocks remain a challenging task. As discussed by Bahrani et al. (2015), ideally a 3D DEM code that could capture all the pre- and post-peak fracturing stages in brittle rocks would be required to realistically simulate drilling-induced core damage and v-shaped notch failure near the excavation. Alternatively, stress paths from 3D continuum models can be combined with two-dimensional (2D) DEM models to simulate brittle rock failure processes.

In this investigation, the latter approach by which the $2 \mathrm{D}$ DEM model previously calibrated to the laboratory properties of undamaged and damaged specimens of LdB granite by Bahrani et al. (2015), is used to investigate the influence of stress path on two specific aspects of brittle rock failure processes: 1) micro-cracks initiation and stress 'memory' effects in brittle rocks; and 2) micro-crack accumulation and depth of stress fracturing around underground excavations. The stress memory, in the Kaiser Effect test, which consists of two loading stages, is evaluated by the stress level in the second loading stage at which the micro-cracks initiated compared to the maximum stress level in the first loading stage that resulted in the generation of micro-cracks. If the two stress levels are equal, the rock specimen is considered to have a memory of its stress state in the first loading stage.

\section{BACKGROUND - DEM MODEL OF LAC DU BONNET GRANITE}

\subsection{Laboratory properties of Lac du Bonnet (LdB) granite}

Evidences of sample disturbance have been documented at the Underground Research Laboratory (URL) in Manitoba (Canada) by Martin and Stimpson (1994) and Eberhardt et al. (1999). They showed that the UCS, Young's modulus, and the P-wave velocity measured on

pg. 6 
cores decreases and the Poisson's ratio increases with increasing sampling depth and consequently increasing in situ stress magnitudes (Fig. 2). They suggest that these effects were caused by increasing micro-crack damage in cores retrieved from greater depths. This was also supported by the strong non-linearity of the stress versus volumetric strain curve from damaged specimens, reflecting the higher volume of closing micro-cracks at the early stage of loading.

At the URL, a proxy for borehole wall damage can be obtained by examining the in-situ sonic velocity logs. Contrary to the velocity measured on cores in the laboratory, the in-situ velocity appeared to be depth independent (Fig. 2a). Note that sudden drops in in-situ p-wave velocity are related to fracture zones. This observation suggests that the intensity of the damage in the cores is more than that in the borehole walls.

\subsubsection{Models of undamaged and damaged LdB granite}

Bahrani et al. (2015) used the DEM code, PFC2D (Itasca 2008) to simulate micro-cracking of the core during drilling with different borehole orientations ${ }^{1}$. In PFC, a brittle rock is simulated as an assemblage of circular particles (disks), cemented at their contact points using a bond model (e.g., parallel bond). This numerical method, called the Bonded Particle Model (BPM), explicitly simulates micro-cracking as bond breakage. In this method, pre-defined complex empirical constitutive relations used in continuum numerical methods are replaced with simpler particle contact/bond logic without requiring plasticity rules. Once a bond breaks in tension or shear, the displacement field as well as the transition to the residual strength are controlled by particle geometry and friction at particle-particle contacts. This approach explicitly captures a

\footnotetext{
${ }^{1}$ Due to the use of the 2D model, the results of this investigation are obviously not representative of the $3 \mathrm{D}$ stress conditions in the core or near the borehole wall. While they are simulating a 2D slot excavation, the findings with respect to damage initiation and stress memory effects in the damaged cores are valid.
} 
fundamental characteristic of brittle failing rocks known as the cohesion weakening frictional strengthening behavior.

The clumped particle modeling approach proposed by Cho et al. (2004) was chosen for this study. A clump consists of multiple circular particles that are glued together in order to behave as a single rigid object. This approach generates irregular shaped particles (similar to rock grains), leading to a more realistic kinematic behavior due to the geometric heterogeneity of the clumps, compared to the conventional PFC model, where grains are simply simulated by circular particles. The algorithm proposed by Cho et al. (2007) was used to convert the conventional bonded particle model to the clumped particle model in a $3.17 \mathrm{~cm} \times 6.34 \mathrm{~cm}$ specimen. Similar to Cho's clump model, the average clump size of $2 \mathrm{~mm}$ was chosen to be equal to the average grain size (diameter) of LdB granite. Note that using a smaller clump size would probably affect calibrated micro-properties. However, this would not change the macro-properties derived from the model, as in PFC the micro-properties are adjusted until the macro-properties are matched with the target values (in this case the uniaxial compressive strength and the elastic modulus). Therefore, the results of a PFC model can be considered independent of the clump size as long as the selected clump size remains small compared to the model size. The selected clump size in the present study fulfills the ISRM suggested method for determining the uniaxial compressive strength of a rock specimen, indicating that the largest grain size should be at least 10 times smaller than the diameter of the rock specimen (Bieniawski and Bernede 1979). The calibration process involved:

1) Calibration of clumped specimen to the properties of undamaged LdB granite including tensile strength $\left(\sigma_{\mathrm{t}}=6.7 \mathrm{MPa}\right)$, Unconfined Compressive Strength $(\mathrm{UCS}=213 \mathrm{MPa})$ and elastic modulus $(\mathrm{E}=65 \mathrm{GPa})$

pg. 8 
2) Application of an approximate coring-induced stress path from a vertical borehole (borehole perpendicular to $\sigma_{3}$ direction) to the undamaged clumped specimen to introduce damage in the form of micro-cracks (Fig. 3a); and

3) Comparison between the properties of damaged clumped specimens with those of damaged $\mathrm{LdB}$ granite specimens $(\mathrm{UCS}=157 \mathrm{MPa}$; and $\mathrm{E}=52 \mathrm{GPa})$.

Table 1 lists the micro-properties obtained from the described calibration procedure. Note that no standard deviation was assigned to the bond strength parameters. Therefore, grain geometric heterogeneity (different shapes and sizes of clumps) is the only source of heterogeneity in the clumped model.

A detailed description of the calibration process is provided by Bahrani et al. (2011, 2015). The stress path experienced by the core during drilling for boreholes perpendicular to (vertical borehole) and parallel with (horizontal borehole) the maximum principal stress $\left(\sigma_{1}\right)$ direction were obtained from a 3D finite element model (Bahrani et al. 2012, 2015). Note: the maximum principal stress is nearly horizontal, and the minimum principal stress is nearly vertical at the URL.

The stress-strain curves of the undamaged and damaged clumped specimens are shown in Fig. 3b. This figure demonstrates that the reduced strength and elastic modulus due to the presence of micro-cracks in the damaged clumped specimen were properly captured. Once the clumped specimens were calibrated to the properties of both undamaged and damaged LdB granite specimens (with simulated coring-induced stress path in the borehole perpendicular to $\sigma_{1}$ ), the stress path experienced during core drilling from a borehole parallel with the $\sigma_{1}$ direction was approximated (grey arrows in Fig. 3c) and applied to the undamaged clumped specimen. Fig. 3d

pg. 9 
compares the stress-strain curves of the undamaged clumped specimen and that with the applied coring-induced stress path of a borehole parallel with the $\sigma_{1}$ direction. The stress-strain curves as well as the calculated UCS and E of these two clumped specimens are essentially identical. Only the post-peak behavior is slightly different.

Fig. 4a and Fig. 4c compare the patterns of coring-induced micro-cracks generated inside the clumped specimens during the unloading stages for boreholes perpendicular to (vertical borehole) and parallel with (horizontal borehole) $\sigma_{1}$ directions, respectively. Note that unloading was simulated by moving the two parallel walls on opposite sides of the PFC model (vertical or horizontal walls) away from each other, while monitoring the reaction forces acting on them from the clumps. The coring-induced micro-cracks in these two specimens are tension cracks and randomly located in the clumped specimens. The orientation of these cracks is sub-parallel to the initial $\sigma_{1}$ direction, thus is either perpendicular to or parallel with the specimen axes depending on the drilling direction.

The locations and orientations of all the cracks (accumulated during both unloading and loading stages) in the clumped specimens at the end of axial loading (at $70 \%$ of the peak strength in the post-peak region), in the cases of boreholes perpendicular to and parallel with the $\sigma_{1}$ direction are presented in Fig. 4b and Fig. 4d, respectively. The cracks in the case of the borehole parallel with $\sigma_{1}$ are oriented approximately parallel to the specimen long axis (Fig. 4d), whereas cracks with orientations perpendicular to the specimen long axis can be seen in the case of the borehole perpendicular to $\sigma_{1}$ direction (Fig. $4 \mathrm{~b}$ ). The difference in the orientations of micro-cracks in these two cases suggests that cracks perpendicular to the specimen long axis were generated during the unloading stage in the case of the borehole perpendicular to $\sigma_{1}$ direction (i.e., vertical borehole;

pg. 10 
Fig. 4a), and their interaction with cracks parallel with the specimen long axis, formed during axial reloading, resulted in the failure of the clumped specimen at an axial stress of $157 \mathrm{MPa}$.

Table 2 compares the laboratory test and clumped specimen calibration results for both undamaged and damaged LdB granite. The mean and standard deviation values of the clumped specimens are obtained from six models with different clumped particle arrangements, but with the same micro-properties. As can be seen from this table, excellent agreement exists between the actual test and numerical simulation results.

\subsection{Strength degradation of damaged LdB granite}

Once the clumped specimens were calibrated to the strength and deformation properties of $\mathrm{LdB}$ granite under unconfined conditions, they were tested for the confined strength. The strengths of undamaged and damaged $\mathrm{LdB}$ granite and those predicted by the clumped specimens at confining pressures up to $60 \mathrm{MPa}$ are compared in Fig. 5.

The strengths of undamaged and damaged LdB granite (Fig. 5a) exhibit a typical nonlinear behavior over the full range of confinement. This is the case for the clumped specimens up to a confining pressure of about $10 \mathrm{MPa}$ (Fig. 5b). Beyond this confining pressure, the strength of the clumped specimen increases linearly with increasing confinement. This resulted in a slight overestimation of the confined strength of both the undamaged and damaged LdB granite for $\sigma_{3}$ $>30 \mathrm{MPa}$. The linear increase in strength with $\sigma_{3}$ in the clumped specimens is interpreted to be due to the assumption that clumps representing rock grains are unbreakable.

In order to quantify the influence of the generated micro-cracks on the strength reduction of damaged specimens from undamaged specimens a Degradation Parameter (DP) (Bahrani and Kaiser 2013, 2017) was introduced:

pg. 11 
$D P=\left(\left(\sigma_{l i}-\sigma_{l d}\right) / \sigma_{l i}\right) \times 100$

where, $\sigma_{l i}$ and $\sigma_{l d}$ are the strengths of undamaged (intact) and damaged specimens, respectively. Fig. 6 shows the degradation parameter, DP, as a function of confinement, normalized to the unconfined compressive strength of undamaged specimens $\left(\mathrm{UCS}_{\mathrm{i}}\right)$. In this figure, the DP values of the clumped specimens and those of LdB granite exhibit a rapid decrease from their initial values (about 25 to 30\%) with increasing confinement. Beyond a normalized confinement of about $\sigma_{3} / \mathrm{UCS}_{\mathrm{i}}=0.1$, the DP of the clumped specimen remains constant at about $5 \%$, a value that is eventually reached by the test data.

Figs. 5 and 6 indicate that although the absolute laboratory strength values of LdB granite (especially at high confinement) could not be predicted by the clumped specimens, the strength degradation caused by unloading-induced micro-cracks resulting in the specimen cohesion loss is well captured by the clumped specimens for the entire range of confinement.

\section{INVESTIGATION OF THE INFLUENCE OF STRESS PATH ON STRESS MEMORY}

The results of numerical simulations presented above (Section 2.2, Fig. 3) indicate that the strength and elastic modulus of the damaged clumped specimen from the simulated core drilled parallel to the $\sigma_{1}$ direction (horizontal borehole) are identical to those of the undamaged clumped specimen. This can be interpreted to be due to the 'stress memory' effect which is discussed in more detail next.

According to the principle of the Kaiser Effect (KE), a material starts to emit acoustic emission (AE) during loading only when the largest previously experienced stress level is exceeded (Lavrov 2003). This phenomenon was first discovered by Joseph Kaiser on small specimens of

pg. 12 
metal, wood and sandstone under tension (Kaiser 1950). Since then, many researchers have investigated the potential of this phenomenon as an inexpensive method for in situ stress determination (e.g., Villaescusa et al. 2002; Lehtonen et al. 2012). In a typical KE test, the cumulative AE count versus axial stress is plotted (schematically shown in Fig. 7). The loading stages while the AE is monitored are as follows:

Stage 1: the specimen is first loaded uniaxially to a given stress level, which is called the Previous Maximum Stress (PMS);

Stage 2: the specimen is unloaded to zero stress; and

Stage 3: the specimen is reloaded beyond the PMS.

As the load in the second cycle approaches the PMS, a rapid increase in AE appears. This point is called the Recalled Maximum Stress (RMS) and the ratio of RMS to PMS is called the Felicity Ratio (FR). The perfect KE is achieved when the FR is unity (Fig. 7a). A Felicity Effect (FE) occurs when the FR is smaller than one (Fig. 7b).

The damage criterion in the Kaiser Effect test (Fig, 8) is the locus of points in a stress space where the criterion of crack growth (i.e., AE) is just satisfied and additional permanent damage develops (Holcomb and Costin 1986; Holcomb 1993). The damage criterion proposed by Holcomb (1993) based on a penny-shaped crack growth model, was studied by Pestman et al. (2001) in the laboratory, and by Holt et al. $(2001,2003)$ using a bonded particle model. In the laboratory tests by Pestman et al. (2001), the horizontal stress components $\left(\sigma_{H}\right.$ and $\left.\sigma_{h}\right)$ for a given stress ratio $\left(\sigma_{H} / \sigma_{h}\right)$ were increased from zero stress until the onset of AE (e.g., Point 1 in Fig. 8). Once the damage state was reached, the horizontal stress components were decreased to prevent further damage. The stress state was then shifted to the next stress ratio, and the stresses

pg. 13 
were increased until the onset of $\mathrm{AE}$ at Point 2 (Fig. 8). This experiment was continued for different values of stress ratios and the Holcomb damage criterion was obtained by mapping all the points, as demonstrated in Fig. 8.

If the damage criterion in the Kaiser Effect test is not reached in the first loading cycle, the specimen in the second loading cycle behaves similar to a 'fresh' specimen. Memory effect in the second cycle occurs when the axial stress exceeds the damage criterion, which is the same as in the first cycle. This means that if the stress path in the first loading cycle passes the damage criterion, the damage criterion will shift, and no stress memory in the second loading cycle is seen until the new damage criterion is reached.

Lavrov (2003) provided a thorough overview of the published theoretical, experimental and numerical investigations on the $\mathrm{KE}$, and raised several fundamental questions that need to be addressed when this method is used to obtain in situ stresses. In the following sections, the calibrated clumped specimen is used to investigate the influence of uniaxial and triaxial stress paths and more complex coring-induced stress paths on the formation of stress memory (i.e., Kaiser Effect) are investigated. This includes five cases with different stress paths presented in Fig. 9 and summarized in Table 3. The stress paths are displayed on plots where the $\mathrm{x}$ - and $\mathrm{y}$ axes represent the lateral $\left(\sigma_{1}\right)$ and axial $\left(\sigma_{a}\right)$ stresses, respectively. Cases 1 to 3 represent relatively simple stress paths similar to those experienced during standard laboratory Kaiser Effect tests. Cases 4 and 5 correspond to the stress paths experienced by a core drilled from the in-situ stress state at the AECL's URL with drilling directions parallel to $\sigma_{1}$ and $\sigma_{3}$, respectively. These stress paths are identical to those presented in Fig. 3a and c. The lateral stress in four of the five cases is the least principal stress $\left(\sigma_{3}\right)$. For Case 5 , it is the maximum principal stress $\left(\sigma_{1}\right)$ prior to unloading. All simulations are completed by uniaxial loading of the clumped specimens

pg. 14 
past the peak strength with the loading direction aligned with the specimen axis. The bond breakage corresponding to micro-crack is monitored until this final loading stage to assess the stress memory effects. A detailed description of the simulation results is provided for each case in the following sections by referring to Figs. 10 to 14.

\subsection{Case 1 - Simple uniaxial stress path}

The calibrated undamaged clumped specimen was first uniaxially loaded to $60 \mathrm{MPa}$ (Stage 1 in Fig. $9 \mathrm{~b}$ and 10). This resulted in the generation of about 1000 micro-cracks (i.e., 1000 broken parallel bonds) initiated at an axial stress of about $25 \mathrm{MPa}$. These cracks were oriented subparallel to the loading direction (specimen long axis). The clumped specimen was completely unloaded at Stage 2 and then reloaded axially at Stage 3 to failure. As shown in Fig. 10, during the reloading stage the cracks started to grow as soon as the axial stress exceeded the Previous Maximum Stress (i.e., $60 \mathrm{MPa}$ ) reflecting a perfect Kaiser Effect with FR = 1.0. Numerical studies by Hunt et al. (2003) with a similar stress path (i.e., loading, unloading and reloading under uniaxial stress condition) confirmed the capability of the bonded particle model to capture the Kaiser Effect observed in the laboratory tests on a sandstone. The clumped specimen failed at an axial stress of $212 \mathrm{MPa}$.

\subsection{Case 2 - Unloading from in-situ condition followed by axial reloading}

The test started at a biaxial stress state $\left(\sigma_{a}=60 \mathrm{MPa}, \sigma_{l}=11 \mathrm{MPa}\right)$ as shown in Fig. 9c and 11. At Stage 1, the lateral stress (grey curve in Fig. 11) was first reduced from $11 \mathrm{MPa}$ to zero while the axial stress (black curve in Fig. 11) was kept constant. Almost 800 micro-cracks were generated during this stage. Similar to the previous case, these cracks were oriented sub-parallel to the specimen long axis. The clumped specimen was unloaded to zero stress at Stage 2 by

pg. 15 
reducing the axial stress to zero from $60 \mathrm{MPa}$, and then reloaded uniaxially until failure at Stage 3. During reloading, similar to the previous case, the cracks started to grow when the axial stress exceeded the Previously Maximum Stress (i.e., PMS $=60 \mathrm{MPa}$ ) in accordance with a perfect Kaiser Effect $(\mathrm{FR}=1.0)$. The clumped specimen failed at an axial stress of $212 \mathrm{MPa}$.

\subsection{Case 3 - loading in confined conditions, unloading and uniaxially reloading}

The undamaged clumped specimen was initialized with a hydrostatic stress of $\sigma_{1}=\sigma_{3}=11 \mathrm{MPa}$ (Fig. 9d and 12). From this stress state, the axial stress $\left(\sigma_{a}\right)$ was increased at Stage 1 from 11 $\mathrm{MPa}$ to $60 \mathrm{MPa}$ while the lateral stress $\left(\sigma_{l}\right)$ was kept constant at $11 \mathrm{MPa}$. As can be seen in Fig. 11, the increase in the cumulative crack number occurs at an axial stress of about $36 \mathrm{MPa}$, which confirms the shift in the damage criterion due to confinement compared to that of Case 1 (i.e., $25 \mathrm{MPa}$ ), where the specimen was uniaxially loaded. The shift in the damage criterion is due to the initial confining pressure of $11 \mathrm{MPa}$. At Stage 2 the axial stress was reduced back to $11 \mathrm{MPa}$. The specimen was unloaded to zero stress by first removing the lateral stress at Stage 3 and then axial stress at Stage 4. The clumped specimen was then loaded uniaxially (Stage 5) to failure. The crack growth was observed at an axial stress of RMS $=28 \mathrm{MPa}$ which results in a Felicity ratio of $28 / 60=0.47$. The clumped specimen failed at an axial stress of $212 \mathrm{MPa}$.

This behavior was observed in the laboratory Kaiser Effect tests conducted by Filiminov et al. (2001) under a similar stress path. They observed distinct AE initiation during the second cycle at a stress level lower than the maximum load in the first cycle (i.e., FR $<1$ ). They suggested that when a specimen, preloaded under triaxial stress state, is reloaded in the second cycle in uniaxial compression in the direction of first cycle $\sigma_{1}$, the distinct AE take-off in the second cycle takes place at $\sigma_{1}^{I I}$ according to the following equation:

pg. 16 
$\sigma_{1}^{I I}=\sigma_{1}^{I}-(K+1) \sigma_{3}^{I}$

where $\sigma_{1}^{I}$ and $\sigma_{3}^{I}$ are the principal stresses of the first loading cycle, and $\mathrm{K}$ is the friction coefficient between crack faces. Filiminov et al. (2001) suggested a K value of about 0.5 to 0.6 for rock salt, which is close to its friction angle of $28^{\circ}$, obtained from triaxial tests over the range of zero to $10 \mathrm{MPa}$ confining pressure. In the numerical analysis described above, $\mathrm{K}$ is calculated to be 1.2 , which is close to the friction coefficient of 1.4 (equivalent friction plus dilation angle of $55^{\circ}$ ) for Lac du Bonnet granite.

The results from Cases 1 to 3 indicate that the clumped specimen captures the behavior observed in laboratory Kaiser Effect tests under both uniaxial and triaxial stress conditions. Note that the direction of axial stress $\left(\sigma_{\mathrm{a}}\right)$ in the second cycle is the same as that in the first cycle in these three cases (i.e., no stress rotation was simulated). Moreover, the damaged clumped specimens fail at the same peak compressive stress when reloaded uniaxially, although they had experienced different stress paths in their previous loading/unloading cycles.

In the following, the concept of stress memory and the Kaiser Effect are used to better understand micro-cracking under stress paths representative for two drilling simulations as described earlier. Fig. 13 (Case 4) and Fig. 14 (Case 5) show the cumulative number of cracks (during unloading and loading stages) versus stress (axial and lateral) for horizontal (parallel to the $\sigma_{1}$ ) and vertical (perpendicular to the $\sigma_{1}$ ) drilling scenarios.

\subsection{Case 4-Drilling in the $\sigma_{1}$ direction (horizontal borehole at the $U R L$ )}

As shown in Fig. 13, in the case of the horizontal borehole, no cracks are generated at Stage 1 when $\sigma_{1}$ (or axial stress, $\sigma_{\mathrm{a}}$ ) is reduced from $60 \mathrm{MPa}$ to $40 \mathrm{MPa}$. The cracks start to grow in the second stage during the reduction of $\sigma_{3}$ (or lateral stress, $\sigma_{1}$ ) from $11 \mathrm{MPa}$ to zero. These cracks, 
as mentioned earlier and shown in Fig. 4c are oriented sub-parallel to the specimen axis. At Stage 3, $\sigma_{1}$ is reduced from $40 \mathrm{MPa}$ to zero and no new cracks are generated. At Stage 4 (i.e., where the specimen is reloaded axially), no new cracks appear until the axial stress reaches 38 MPa. This stress level (i.e., RMS) corresponds to the stress level at which the first crack was generated during unloading (i.e., Stage 2), and is less than the Previous Maximum Stress (i.e., 60 $\mathrm{MPa}$ ). Therefore, the Felicity Ratio, the ratio of RMS to PMS, is $38 / 60=0.63$. Note that no stress rotation has occurred and the UCS of the damaged clumped specimen is the same as that of the undamaged specimen (i.e., $212 \mathrm{MPa}$ ).

\subsection{Case 5 - Drilling in $\sigma_{3}$ direction (vertical borehole at the URL)}

In the case of the simulated core drilled from the vertical borehole (borehole perpendicular to the $\sigma_{1}$ direction), the cracks are generated as soon as $\sigma_{3}$ (axial stress in this case) is reduced from 11 MPa to zero (Fig. 14). As discussed earlier and shown in Fig. 4a, these micro-cracks are oriented perpendicular to the specimen axis. In the second stage, when $\sigma_{1}$ (lateral stress in this case) is reduced to zero no new cracks are generated. At Stage 3, the clumped specimen is loaded axially, which means that the maximum principal stress direction has been rotated by $90^{\circ}$; from perpendicular to parallel to the specimen axis. At this stage, cracks initiate at an axial stress (RMS) of $22 \mathrm{MPa}$. This stress level corresponds neither to the Previous Maximum Stress experienced by the specimen $(\mathrm{PMS}=60 \mathrm{MPa})$, nor to the stress component parallel to the borehole orientation (i.e., parallel to the specimen axis during unloading stage, $\sigma_{3}=11 \mathrm{MPa}$ ). The Felicity Ratio, is calculated to be $22 / 60=0.37$. As can be seen from Fig. 14, only in this case is the UCS of the damaged clumped specimen less than that of the undamaged specimen. This is attributed to stress rotation (see change in the direction of $\sigma_{1}$ in the two inserts in Fig. 14).

pg. 18 
The experimental investigation by Holcomb and Costin (1986) and experimental and numerical investigations by Lavrov et al. (2002) indicate that specimens for uniaxial laboratory compression in the Kaiser Effect test should be retrieved as close as possible to the direction of maximum principal stress. They found that the Kaiser Effect is only properly observed when the deviation of reloading direction from $\sigma_{1}$ axis is less than $10^{\circ}$. In the laboratory tests performed on Brazilian disks by Lavrov et al. (2002), the disks were subjected to two loading cycles with or without disk rotation angle between the two cycles. Lavrov et al. (2002) report that in the case of disk rotation angle of $7.5^{\circ}$, the AE take-off occurred close to the first cycle maximum load (i.e., FR close to unity), whereas in the case of disk rotation of $15^{\circ}$, the AE take-off happened at an axial stress, which is about half of the first cycle maximum load (FR close to 0.5 ). The results of loading the damaged clumped specimens in the case of the borehole perpendicular to the $\sigma_{1}$ direction support the findings of Holcomb and Costin (1986) and Lavrov et al. (2002); no Kaiser effect exists when the deviation of the loading direction from in situ $\sigma_{1}$ axis is $90^{\circ}$.

It is known that stress rotation during tunnel advance can create damage oriented at angles other than the final excavation boundary-parallel crack directions, which may result in strength reduction ahead of the tunnel face (Eberhardt 2001; Diederichs et al. 2004). The reduced strength of the simulated damaged core drilled from the vertical borehole compared to the strengths of undamaged clumped specimen and the simulated damaged core drilled from the horizontal borehole is largely due to the rotation of the maximum principal stress from perpendicular to the specimen axis during unloading stage to parallel to the specimen axis in the reloading stage. This results in a complete disappearance of stress memory in the damaged clumped specimen as shown in Fig. 14.

pg. 19 
During loading of the damaged clumped specimen with the simulated coring stress path of horizontal borehole (Case 4, where no stress rotation exists), almost no additional micro-cracks developed before the unloading crack initiation stress level is reached (i.e., $40 \mathrm{MPa}$ in Fig. 13). However, micro-cracks were generated early on during reloading of the simulated core drilled from the vertical borehole (Case 5, at $22 \mathrm{MPa}$ in Fig. 14). This resulted in an accumulation of more micro-cracks by the time the crack initiation stress level in the previous unloading stage is reached, which in turn resulted in a weaker clumped specimen compared to the damaged clumped specimen with the simulated coring stress path of the horizontal borehole. This is in accordance with field observation by Martin and Christiansson (1991) at the 240-level of the URL, showing that overcored samples from boreholes drilled perpendicular to the $\sigma_{1}$ direction had more stress-induced micro-cracks than those drilled parallel with the $\sigma_{1}$ direction.

\subsection{Limitations of this $2 D$ investigation}

The coring stress paths obtained from the 3D finite element model are much more complex than those applied in this study. In the approximate stress paths applied to the clumped specimens, one of the principal stresses $\left(\sigma_{1}\right.$ or $\left.\sigma_{3}\right)$ was decreased at a time and no stress rotation during unloading stages was simulated. This resulted in the generation of micro-cracks which were either sub-parallel or sub-perpendicular to the specimen axis. In the actual coring stress paths, obtained from the $3 \mathrm{D}$ finite element model, the stress components continuously rotate relative to the borehole axis as the core is drilled out. Applying such a complex stress path to the clumped specimen would have resulted in the generation of micro-cracks obliquely aligned to the

specimen axis. Micro-cracks oriented at a variety of angles intersected by preferred oriented micro-cracks in certain quartz grains were observed by Eberhardt et al. (1999) in the damaged samples retrieved from the 420-level of the URL. Such inclined micro-cracks may cause further

pg. 20 
alteration to the damage criterion, stress memory formation, and strength reduction in the core retrieved from borehole parallel to the $\sigma_{1}$ direction. The impact of crack damage due to inclined cracks is not captured by this study. However, this investigation clearly demonstrates that stress path influences crack damage and stress memory. It follows that in situ stress estimations using the Kaiser Effect can be flawed if the cause for lower FRs is not recognized and boreholes are not properly oriented.

\section{INFLUENCE OF STRESS PATH ON DEPTH OF STRESS FRACTURING NEAR UNDERGROUND OPENING}

\subsection{Background}

Brittle failure in the form of $\mathrm{v}$-shaped notch was observed around the mine-by-experiment tunnel at the 420-level of the URL, Canada. The experiment was conducted in a massive, sparsely fractured rock mass and the v-shaped notch failure with a depth of up to $0.5 \mathrm{~m}$ around the tunnel did not interact with any major joints or fractures (Fig. 1b). According to the results of stress measurements, the maximum and minimum principal stresses are $60 \mathrm{MPa}$ and $11 \mathrm{MPa}$ in magnitude, and oriented nearly horizontal and vertical, respectively. The mine-by-experiment tunnel excavated in the direction of the intermediate principal stress provides a suitable case for a two-dimensional stability analysis.

The Kirsch equation indicates that the maximum tangential stress in elastic rock should reach $169 \mathrm{MPa}$ at the tunnel roof. The average uniaxial compressive strength of undamaged specimens of LdB granite is $213 \mathrm{MPa}$. If the latter were considered representative of the tunnel wall strength (assuming GSI=100), no compressive failure should have occurred around the tunnel since the strength would be about $25 \%$ higher than the maximum tangential stress.

pg. 21 


\subsection{Review of previous numerical investigations}

Hadjiabdolmajid et al. (2002) showed that for a rock mass strength of $128 \mathrm{MPa}$ (i.e., GSI=80) in an elastic model a very thin zone with a factor of safety of less than unity is developed in the region of the notch. A more realistic simulation of progressive failure and notch formation in an elastic model can be performed by iteratively removing failed elements. In this approach, as explained by Martin (1997), the finite elements with strength factors of less than unity are identified and removed. The analysis is then repeated with the new geometry. This process is continued until the final notch profile is achieved. Martin (1997) found that the depth of failure in this approach is over-predicted by a factor of 2 to 3 . This approach is also dependent on the type and size of the mesh elements.

Hajiabdolmajid et al. (2002) also used elastic-perfectly plastic and elastic-brittle constitutive models with an unconfined rock mass strength of $128 \mathrm{MPa}$ and found that these two approaches underestimate the depth of failure. Brittle rock failure processes involve a loss of cohesive strength by tensile cracking at the early stages of loading, and the mobilization of frictional strength component when the cohesional strength component is significantly reduced (Martin and Chandler 1994). Therefore, a constitutive model that can capture the delay in frictional strength mobilization should simulate rock brittle failure processes more realistically. Hajiabdolmajid et al. (2002) adopted a strain dependent cohesion-weakening frictionalstrengthening (CWFS) model where the residual cohesion and friction angle values are assigned to the model as a function of plastic shear strain. Using the strain-dependent CWFS model, Hajiabdolmajid et al. (2002) could capture the shape of the v-shaped notch observed at the URL. The assumption for the rock mass strength in their analysis was $128 \mathrm{MPa}$. Diederichs (2007) used an instantaneous CWFS model with the Hoek-Brown strength parameters and a rock mass 
strength of $100 \mathrm{MPa}$. This approach is similar but simpler than that adopted by Hajiabdolmajid et al. (2002), as the cohesive strength reduction and frictional strength increase are independent of plastic shear strain.

Using an elastic model, Cai and Kaiser (2013) found that the tunnel boundary irregularities can increase the induced stresses to as high as $240 \mathrm{MPa}$, higher than the average unconfined compressive strength of $213 \mathrm{MPa}$ obtained from the laboratory test. Considering the effect of tunnel boundary irregularities in a strain-independent CWFS model, Cai and Kaiser (2013) simulated the observed progressive brittle failure leading to the formation of v-shaped notch. Using this approach, the in situ rock mass spalling strength was estimated to be about $80 \%$ of the strength of the undamaged LdB granite under an unconfined condition (i.e., UCS of about $175 \mathrm{MPa})$.

The Distinct Element Method (DEM) has also been used by different researchers to simulate stress fracturing around underground openings, particularly the URL's mine-by-experiment tunnel. Potyondy and Cundall (2004) used PFC2D (Itasca 2008) and calibrated the model to the UCS of undamaged LdB granite. They found that the observed failure can only be captured either by increasing the far-field stresses or monotonically reducing the bond strength. In the latter case, they found that the v-shaped notch failure could be captured by applying a strength reduction factor of 0.6 to the bond strength. The UCS of the PFC model in this case is estimated to be $60 \%$ of that of LdB granite, about $120 \mathrm{MPa}$. Hazzard and Young (2004) used the same model and micro-properties and ran the model in dynamic mode with low numerical damping. The UCS of this model is estimated to be less than $120 \mathrm{MPa}$, due to the use of low numerical damping (Hazzard and Young 2000). The seismicity simulated by the dynamically run PFC 
model by Hazzard and Young (2004) was comparable to the actual seismicity recorded around the mine-by experiment tunnel at URL, in terms of the locations and magnitudes of the events.

Shin (2010) calibrated an unbreakable grain-based model (GBM) in UDEC to the direct tensile strength, Brazilian strength and unconfined and confined compressive strengths of undamaged LdB granite. In UDEC-GBM, a rock is simulated with polygonal grains, and the grains are assumed to be unbreakable. Shin (2010) demonstrated that when a strain-dependent CWFS model is used for the grain boundaries, a more realistic volumetric strain can be predicted than when a strain-independent CWFS model is used. He then used the UDEC-GBM model, calibrated to the laboratory properties of undamaged LdB granite, (i.e., UCS of $205 \mathrm{MPa}$ ) to simulate the stress fracturing and notch failure around the URL's mine-by experiment tunnel. He found a reasonable agreement between the profile of the v-shaped notch with the depth of damaged zone simulated by the UDEC-GBM. A slight underestimation of the depth of failure by the UDEC-GBM was explained by the fact that the removal of the damaged zone and the resultant stress redistribution were not simulated.

Very recently, Vazaios et al. (2018) used a 2D Finite-Discrete Element Method (FDEM) and was able to realistically simulate the progressive stress fracturing leading to the formation of $\mathrm{v}$ shaped notch around the URL's mine-by experiment tunnel. The uniaxial compressive strength of the rock mass model used to simulate the observed failure was $120 \mathrm{MPa}$.

This review of previous numerical investigations indicates, with the exception of Shin (2010), that the strength of the rock mass back-calculated using numerical simulations is less than the UCS of undamaged LdB granite obtained from laboratory tests (i.e., $<213 \mathrm{MPa}$ ). A summary of this review is presented in Table 4 . The close agreement in the results of UDEC-GBM model by Shin (2010) with an assumed undamaged UCS of $205 \mathrm{MPa}$ with the observed v-shaped notch is 
interpreted to be due to two factors: the adopted strength model for the grain boundaries (i.e., strain-dependent CWFS) and the assumed geometric heterogeneity. The validity of the latter factor, which was not captured in the other studies reviewed above, is investigated next.

\subsection{Indirect approach to estimate depth of stress fracturing near the URL's mine-by-tunnel}

Micro-cracks typically initiate at the grain boundaries that usually constitute the weakest points in a massive rock with little or no defects. This is promoted by the heterogeneous nature of brittle rocks at the grain scale, which results in the generation of tensile stresses even under overall compressive loading condition. As discussed by Diederichs (2007) and Valley et al. (2010), these tensile stresses facilitate brittle rock failure process.

An ideal numerical model to simulate stress fracturing around a tunnel would be one that includes the entire tunnel excavation and captures the effect of grain scale heterogeneities. Such a model would be able to capture grain-scale crack initiation, propagation, coalescence and the development of fractures to a scale relevant for tunnel wall stability considerations. However, this would require discretizing the problem domain over more than three orders of magnitude leading to excessive memory and computing power requirements. Thus, rock grains and smallscale heterogeneities are usually not explicitly simulated in numerical models of tunnel simulation. For this reason, equivalent continuum models with complex constitutive material behaviors are still needed and widely used to predict failure at the rock mass scale (e.g., tunnel). Some researchers tried to overcome these limitations by coupling continuum and discontinuum codes (Potyondy and Cundall 2004; Cai et al. 2007; Katsaga and Potyondy 2012; Lan et al. 2013).

pg. 25 
In this study, an indirect approach is adopted, whereby components of continuum and discontinuum codes are combined to simulate stress fracturing around the mine-by-experiment tunnel at the URL (similar to the simulation of core drilling). This approach is based on the application of 2D stress paths at points on and near the tunnel boundary, obtained from a continuum model, on the previously calibrated clumped specimen, where rock grain-scale geometric heterogeneity and therefore grain-scale fracturing is explicitly captured.

First, the 2D finite element program $\mathrm{RS}^{2}$ (by Rocscience) was used to simulate the mine-byexperiment tunnel with the laboratory properties of undamaged LdB granite. The $\mathrm{RS}^{2}$ model input parameters are listed in Table 5. The internal pressure reduction approach was adopted to simulate a pseudo-3D tunnel excavation in a 2D model. This approach, as discussed in Section 2.6, does not generate out-of-plane cracks and therefore does not account for stress-rotation effects on rock damage near and ahead of the tunnel face.

Fig. 15a shows the $\sigma_{1}$ contours around the tunnel as well as elements yielded in tension at the sides of the tunnel for a tensile strength of 6.7 MPa. As expected, no elements yielded in shear or tension at the tunnel roof, where the maximum tangential stress is $169 \mathrm{MPa}$ and the rock behavior remained elastic for a UCS $=213 \mathrm{MPa}$. Fig. 15b presents a close-up view with seven monitoring points located at or near the excavation boundary and in the center of the observed zone of failure by spalling. The farthest point (\#7) in Fig. 15 is above the observed notch and just beyond the zone where micro-seismic events were detected (Fig. 16a).

The stress paths for the seven monitoring points are plotted in the $\sigma_{1}-\sigma_{3}$ stress space in Fig. $16 \mathrm{~b}$. Due to the 2D simplification, the stress paths here are simpler (linear) compared to those obtained by 3D models (Martin 1997; Read et al. 1998). The laboratory crack initiation stress level (Martin 1997) is also shown in this figure. The stress paths at Point \#1 to Point \#6 exceed

pg. 26 
the crack initiation criterion, whereas the stress path of Point \#7, located just above the notch (Fig. 16a), approaches but never reaches the crack initiation stress level. A point between \#6 and \#7 therefore defines the extent of the excavation damaged zone, consistent with the damage limit of $70 \mathrm{MPa}$ shown in Fig. 16a.

The stress paths shown in Fig. 16b were then applied to the calibrated undamaged clumped specimen $(\mathrm{UCS}=213 \mathrm{MPa})$. Fig. 16c shows the micro-cracks (failed bonds) at the end of stress paths. It can be seen from this figure that the level of damage in the clumped specimens decreases rapidly with increasing distance from the excavation wall (i.e., with increasing confinement). Interestingly, for the point located outside of the observed failure zone and below the crack initiation threshold, the corresponding stress path generated very little damage. This is consistent with the extent of micro-seismic events detected in the field (Hadjiabdolmajid et al. 2002).

Comparing the results of finite element analysis (Fig. 15) and clumped specimens (Fig. 16), it is concluded that although the UCS of rock models in both cases are the same (both $213 \mathrm{MPa}$ ), only the clumped specimens capture the stress fracturing and predicts the extent of damaged zone observed in the field. This is attributed to the grain-scale geometric heterogeneity implemented to the clumped specimen, which causes the generation of tensile stresses between the clumps (grains) during compressive loading, and the initiation of micro-cracks at a stress level which is well below the peak strength. Unfortunately, the adopted approach does not allow to simulate the spalling process. It is postulated that the simulation of spalling process would require the application of the actual 3D stress path (similar to that shown in Fig. 1). 


\section{CONCLUSIONS}

Pre-peak micro-fracturing processes developed during compressive loading of brittle rocks (crack initiation, accumulation and coalescence) and the associated rock damage needs to be considered when dealing with rock mechanics problems involving drilling-induced core damage, which may influence the results of standard rock mechanics laboratory tests (e.g., UCS and elastic modulus), in situ stress measurements based on rock strain (i.e., overcoring techniques), strength (i.e., borehole breakout) and stress memory (i.e., Kaiser effect test). Homogeneous, continuum numerical approaches do not explicitly simulate the pre-peak micro-fracturing stages, and therefore are not suitable for investigating the impact of stress-fracturing. In a review presented in this article of past research efforts, it was shown that continuum and most discontinuum numerical approaches were required to assume a lower rock strength than the average intact strength determined from laboratory tests, to be able to estimate the depth of vshaped notch failure around the mine-by-experiment tunnel at the AECL's URL. It was demonstrated that the discontinuum modelling approach used in this study (i.e., clumped particle model) calibrated to the laboratory properties of undamaged LdB granite estimated the depth of stress-fracturing without requiring any assumption on the rock strength. This is due to the ability of this modeling approach to simulate the grain-scale geometric heterogeneity and pre-peak fracturing processes. These processes were shown to control the amount and orientations of drilling-induced core damage, stress memory in cored samples and the extent of stress fracturing near underground openings.

Various stress paths representative for those followed during laboratory Kaiser effect tests and core drilling from boreholes of various orientations were applied to a clumped specimen, previously calibrated to the laboratory properties of undamaged (intact) LdB granite. The stress 
level associated with crack initiation in the last loading stage and the peak strength were determined in all simulations. It was found that the damaged specimen experiencing the stress path representative for drilling a core from a borehole perpendicular to the $\sigma_{1}$ direction (vertical borehole at URL) had a lower strength compared to that of the damaged specimen experiencing the stress path representative for drilling a core from a borehole parallel with the $\sigma_{1}$ direction (horizontal borehole). This can be explained by the notion of stress memory (i.e., Kaiser Effect). No new micro-cracks were generated during re-loading the damaged specimens from the horizontal borehole, until the maximum stress level previously experienced by the specimen (during drilling process) was reached. However, in the case of a damaged specimen taken from the vertical borehole, new micro-cracks initiated and accumulated early on during the reloading stage (before reaching the previous maximum stress level). This was interpreted to be due to the rotation of maximum principal stress direction from the original stress state (perpendicular to the specimen axis) to the applied loading direction (parallel with the specimen axis). Such a stress rotation resulted in a weaker specimen, in accordance with previous laboratory tests on Brazilian disks and field observations at the URL.

In the case of stress fracturing around the mine-by-experiment tunnel, the stress paths obtained from a $2 \mathrm{D}$ model were applied to the previously calibrated numerical specimens. It was found that the amount of damage decreases with increasing distance from the excavation boundary due to the increase in confinement. It is concluded that the extent of stress fracturing in the tangential stressed roof or floor at the AECL's URL could have been predicted by applying a 2D stress path on a well calibrated DEM model that considers the grain-scale geometric heterogeneity and prepeak fracturing processes in an overall compressive loading condition. 
The limitation of the adopted numerical approach is that true $3 \mathrm{D}$ stress paths had to be approximated. Unfortunately, this prevented to detailed study of inclined micro-cracks generated during stress rotation. The simulation of the true $3 \mathrm{D}$ stress paths in a core during drilling or a point at the wall of an advancing tunnel (as illustrated in Fig. 1) remains a challenge using the adopted numerical approach, and therefore deserves further investigations. The 3D coupled continuum-discontinuum numerical approach will likely be the future solution for solving rock mechanics problems such as the simulation of stress fracturing and spalling and the estimation of depth of failure near the walls of an advancing tunnel or a borehole as well as the drillinginduced core damage, which may lead to an alteration in the results of laboratory tests on rock samples and in situ stress measurements.

\section{ACKNOWLEDGEMENTS}

The authors wish to acknowledge the support by MIRARCO at Laurentian University, Itasca Consulting Group through the Itasca Education Partnership (IEP) program, and the Natural Sciences and Engineering Council of Canada (NSERC). The authors would also like to thank Drs. Derek Martin and Erik Eberhardt for many insightful discussions and for providing LdB granite laboratory test data.

\section{REFERENCES}

Bahrani, N., and Kaiser, P.K. 2013. Strength degradation of non-persistently jointed rockmass. International Journal of Rock Mechanics and Mining Sciences, 62: 28-33.

Bahrani, N., and Kaiser, P.K. 2017. Estimation of confined peak strength of crack-damaged rocks. Rock Mechanics and Rock Engineering, 50: 309-326.

Bahrani, N., Kaiser, P.K., and Valley, B. 2014. Distinct element method simulation of an analogue for a highly interlocked, non-persistently jointed rockmass. International Journal of Rock Mechanics and Mining Sciences, 71: 117-130. 
Bahrani, N., Valley, B., and Kaiser, P.K. 2011. Discrete element modeling of drilling-induced core damage and its influence on laboratory properties of lac du Bonnet granite. In Proceedings of the $45^{\text {th }}$ US rock mechanics/Geomechanics Symposium, San Francisco, CA, 9p.

Bahrani, N., Valley, B., and Kaiser, P.K. 2015. Numerical simulation of drilling-induced core damage and its influence on mechanical properties of rocks under unconfined condition. International Journal of Rock Mechanics and Mining Sciences, 80: 40-50.

Bahrani, N., Valley, B., Maloney, S., and Kaiser, P.K. 2012. Numerical investigation of the influence of borehole orientation on drilling-induced core damage. In Proceedings of Eurock2012, Stockholm, Sweden, 13p.

Bieniawski, Z.T., and Bernede, M.J. 1979. Suggested methods for determining the uniaxial compressive strength and deformability of rock materials. International Journal of Rock Mechanics and Mining Sciences \& Geomechanics. Abstract,16(2): 138-140.

Cai, M., and Kaiser, P.K. 2013. In-situ rock spalling strength near excavation boundaries. Rock Mechanics and Rock Engineering, 47(2): 659-675.

Cai, M., Kaiser, P.K., Morioka, H., Minami, M., Maejima, T., Tasaka, Y., and Kurose, H. 2007. FLAC/PFC coupled numerical simulation of AE in large-scale underground excavations. International Journal of Rock Mechanics and Mining Sciences, 44: 550-564.

Cho, N., Martin, C.D., and Sego, D.C. 2007. A clumped particle model for rock. International Journal of Rock Mechanics and Mining Sciences, 44: 997-1007.

Corthesy, R., and Leite, M.H. 2008. A strain softening numerical model of core discing and damage. International Journal of Rock Mechanics and Mining Sciences, 45: 329-350.

Diederichs, M.S. 1999. Instability of hard rockmass: the role of tensile damage and relaxation. Ph.D. thesis, University of Waterloo, Waterloo, ON, Canada.

Diederichs, M.S. 2007. The 2003 Canadian Geotechnical Colloquium: Mechanistic interpretation and practical application of damage and spalling prediction criteria for deep tunnelling. Canadian Geotechnical Journal, 44: $1082-1116$.

Diederichs, M.S., Kaiser, P.K., and Eberhardt, E. 2004. Damage initiation and propagation in hard rock during tunneling and the influence of near-face stress rotation, International Journal of Rock Mechanics and Mining Sciences, 41: 785-812.

Eberhardt, E. 2001. Numerical modeling of three-dimensional stress rotation ahead of an advancing tunnel face, International Journal of Rock Mechanics and Mining Sciences, 38: 499-518.

Eberhardt, E., Stead, D., and Stimpson, B. 1999. Effects of sample disturbance on the stress-induced microfracturing characteristics of brittle rock. Canadian Geotechnical Journal, 36: 239-250.

Filimonov, Y.L., Lavrov, A.V., Shafarenko, Y.M., and Shkuratnik, V.L. 2001. Momery effects in rock salt under triaxial stress state and their use for stress measurement in a rock mass. Rock Mechanics and Rock Engineering, 34: $275-291$.

Gao, F., Stead, D., and Elmo, D. 2016. Numerical simulation of microstructure of brittle rock using a grainbreakable distinct element grain-based model. Computers and Geotechnics, 78: 203-217.

Griffith, A.A. 1924. Theory of rupture. In Proceedings of the $1^{\text {st }}$ International Congress in Applied Mechanics, Delft, pp. 55-63.

Hadjiabdolmajid, V., Kaiser, P.K., and Martin, D.C. 2002. Modeling brittle failure of rock. International Journal of Rock Mechanics and Mining Sciences, 39: 731-741.

Hazzard, J.F., and Young, R.P. 2000. Micromechanical modeling of cracking and failure in brittle rocks. Journal of Geophysical Research, 105(B7): 16683-16697.

Hazzard, J.F., and Young, R.P. 2004. Dynamic modeling of induced seismicity. International Journal of Rock Mechanics and Mining Sciences, 41(8): 1365-1376.

Holcomb, D.J. 1993. Observation of the Kaiser effect under multiaxial stress state: implications for its use in determining in situ stress. Geophysical Research Letters, 20: 2119-2122. 
Holcomb, D.J. and Costin, L.S. 1986. Detecting damage surfaces in brittle materials using acoustic emissions. Journal of Applied Mechanics, 53: 536-544.

Holt, R.M., Doornhof D., and Kenter, C.J. 2003. Use of discrete particle modeling to understand stress-release effects on mechanical and petrophysical behavior of granular rocks. In Numerical modeling in micromechanics via particle methods. Edited by Konietsky H, Swers \& Zeitlinger, Lisse, pp. 269-276.

Holt, R.M., Pestman B.J., and Kenter, C.J. 2001. Use of a discrete particle model to assess feasibility of core based stress determination. In Rock mechanics in the national interest, Vol 2, Proceedings of the $38^{\text {th }}$ US symposium of rock mechanics, Edited by Elsworth D, Tinucci JP, Heasley KA, Washington DC, Swers \& Zeitlinger, Lisse, pp. 1361-1366.

Hunt, S.P., Meyers, A.G., and Louchnikov, V. 2003. Modelling the Kaiser effect and deformation rate analysis in sandstone using the discrete element method. Computers and Geotechnics, 30: 611-621.

Itasca, 2008. Particle Flow Code in 2 dimensions (PFC2D), Ver. 4.0. Minneapolis.

Kaiser, J. 1950. An investigation into the occurrence of noises in tensile tests or a study of acoustic phenomena in tensile tests. Ph.D. Thesis, Tech. Hosch. Munchen, Munich, Germany.

Kaiser, P.K., Yazici, S., and Maloney, S. 2001. Mining-induced stress change and consequences of stress path on excavation stability - a case study. International Journal of Rock Mechanics and Mining Sciences, 38: 167-180.

Katsaga, T., and Potyondy, D.O. 2012. A generic stope model for investigation of fracturing mechanisms in deep gold mines. In Proceedings of the $46^{\text {th }}$ US Rock Mechanics Symposium, Chicago, USA.

Lan, H., Martin, C.D., and Hu, B. 2010. Effect of heterogeneity of brittle rock on micromechanical extensile behavior during compression loading. Journal of Geophysical Research, 115: B01202.

Lan, H., Martin, C.D., and Andersson, J.C. 2013. Evolution of in situ rock mass damage induced by mechanicalthermal loading, Rock Mechanics and Rock Engineering, 46: 153-168.

Lavrov, A. 2003. The Kaiser effect in rocks: principles and stress estimation techniques. International Journal of Rock Mechanics and Mining Sciences, 40: 151-171.

Lavrov, A., Vervoort, A., Filimonov, Y., Wevers, M., and Mertens, J. 2002. Experimental and numerical study of the Kaiser effect in cyclic Brazilian tests with disk rotations. International Journal of Rock Mechanics and Mining Sciences, 39: 287-302.

Lehtonen, A., Cosgrove, J.W., Hudson, J.A., and Johansson, E. 2012. An examination of in situ rock stress estimation using the Kaiser effect. Engineering Geology, 124: 24-37.

Li, Y., and Schmitt, D.R. 1997. Effects of Poisson's ratio and core stub length on bottomhole stress concentrations. International Journal of Rock Mechanics and Mining Sciences, 34: 761-773.

Li, Y., and Schmitt, D.R. 1998. Drilling-induced core fractures and in situ stress. Journal of Geophysical Research, 103: 5225-5239.

Lim, S.S., and Martin, C.D. 2010. Core disking and its relationship with stress magnitude for Lac du Bonnet granite. International Journal of Rock Mechanics and Mining Sciences, 47: 254-264.

Lim, S.S., Martin, C.D., and Akesson, U. 2012. In situ stress and microcracking in granite cores with depth. Engineering Geology, 147-148: 1-13.

Martin, C.D., and Chandler, N.A. 1994. The progressive fracture of Lac du Bonnet granite. International Journal of Rock Mechanics and Mining Sciences and Geomechanics Abstracts, 31: 643-659.

Martin, C.D. 1993. The strength of massive Lac du Bonnet granite around underground openings. Ph.D. thesis, University of Manitoba, 278p.

Martin, C.D. 1997. The $17^{\text {th }}$ Canadian Geotechnical Colloquium: The effect of cohesion loss and stress path on brittle rock strength. Canadian Geotechnical Journal, 34: 698-725.

Martin, C.D., and Christiansson, R. 1991. Overcoring in highly stressed granite - the influence of microcracking. International Journal of Rock Mechanics and Mining Sciences and Geomechanics Abstracts, 28(1): 53-70.

Martin, C.D., and Stimpson, B. 1994. The effect of sample disturbance on the laboratory properties of Lac du Bonnet granite. Canadian Geotechnical Journal, 31: 692-702. 
Pestman, B.J., Kenter, C.J., and Van Munster, J.G. 2001. Core-based determination of in situ stress magnitudes. In Proceedings of the US Rock Mechanics Symposium, Washington, DC, Rotterdam: A.A. Balkema.

Potyondy, D.O., and Cundall, P.A. 2004. A bonded particle model for rock. International Journal of Rock Mechanics and Mining Sciences, 41: 1329-1364.

Read, R.S., Chandler, N.A., and Dzik, E.J. 1998. In situ strength criteria for tunnel design in highly stressed rock masses. International Journal of Rock Mechanics and Mining Sciences, 35(3): 261-278.

Shin, S.W. 2010. Excavation disturbed zone in Lac du Bonnet granite. Ph.D. thesis, Department of Civil and Environmental Engineering, University of Alberta, Edmonton, AB, Canada, 224p.

Valley, B., Suorineni, F.T., and Kaiser, P.K. 2010. Numerical analyses of the effect of heterogeneities on rock failure process. In Proceedings of the $44^{\text {th }}$ US Rock Mechanics Symposium, Salt Lake City, USA, 10p.

Vazaios, I., Vlachopoulos, N., and Diederichs, M.S. 2018. The mechanical analysis and interpretation of the EDZ formation around deep tunnels within massive rockmasses using a hybrid finite-discrete element approach: the case study of the AECL URL tunnel. Canadian Geotechnical Journal, https://doi.org/10.1139/cgj-2017-0578

Villaescusa, E., Seto, M., and Baird, G. 2002. Stress measurement from oriented core. International Journal of Rock Mechanics and Mining Sciences, 39(5): 603-615.

Zang, A., and Stephansson, O. 2010. Stress field of the Earth's crust. Springer Science \& Business Media, 324p.

\section{FIGURE CAPTIONS}

Figure 1 a) Comparison of stress paths at the tunnel wall during tunnel advance (after Read et al. 1998), and in a core during drilling (after Bahrani et al. 2015) obtained from elastic continuum models. b) Tunnel wall failure in the form of v-shaped notch (modified from Martin 1997, with permission from Dr. Martin) and c) drilling-induced core damage observed at the 420-level of the URL (modified from Martin and Stimpson 1994, with permission from Dr. Martin).

Figure 2 Laboratory and in-situ rock properties with increasing depth at URL (modified after Martin and Stimpson 1994)

Figure 3 a) Computed stress path in a core using a 3D elastic FEM (dashed curve) and approximate stress path (grey arrows) applied to the clumped specimen for the case of a vertical borehole drilled perpendicular to $\sigma_{1}$ direction; b) comparison between stress-strain curves of undamaged and damaged clumped specimens after applying the approximate stress path of a 
core drilled from a vertical borehole perpendicular to $\sigma_{1}$ direction; c) computed stress path in a core using a 3D elastic FEM (dashed curve) and approximate stress path (grey arrows) applied to the clumped specimen for the case of a horizontal borehole drilled parallel to $\sigma_{1}$; and $\mathrm{d}$ ) comparison between stress-strain curves of undamaged and damaged clumped specimens after applying the approximate stress path of a core drilled from a horizontal borehole parallel with $\sigma_{1}$. (after Bahrani et al. 2015, with permission from Elsevier)

Figure 4 a) coring-induced micro-cracks in the case of borehole perpendicular to $\sigma_{1}$ (vertical borehole); b) micro-cracks generated from the beginning of the test up to $70 \%$ of the peak in the post-peak region, in the case of borehole perpendicular to $\sigma_{1}$; c) coring-induced micro-cracks in the case of borehole parallel with $\sigma_{1}$ (horizontal borehole); d) micro-cracks generated from the beginning of the test up to $70 \%$ of the peak in the post-peak region, in the case of borehole parallel with $\sigma_{1}$. (after Bahrani et al. 2012)

Figure 5 a) Strengths of undamaged (intact) and damaged LdB granite from laboratory tests; b) strengths of undamaged and damaged clumped specimens.

Figure 6 Strength degradation graph showing the consistency between the degradation parameter (DP) of damaged LdB granite and that of clumped specimen.

Figure 7 Schematic Acoustic Emission (AE) versus axial stress for Kaiser Effect test on a virgin rock: a) a perfect KE occurs when the Recalled Maximum Stress (RMS) is the same as the Previous Maximum Stress (PMS); b) the Felicity Effect occurs when the RMS is less than the PMS. 
Figure 8 Schematic graph of the stress path in the laboratory tests by Pestman et al. (2001) and the generation of Holcomb damage criterion on $\sigma_{\mathrm{H}}-\sigma_{\mathrm{h}}$ stress space (after Zang and Stephansson 2010).

Figure 9 Stress paths used for the study of the stress memory effects: a) stress component orientation for axial $\sigma_{a}$ and lateral $\sigma_{l}$ stresses, and b) to f) for Cases 1 to 5 . All five cases are finally reloaded in the uniaxial condition to investigate the stress magnitude at which microcracking is reactivated (formation of new micro-cracks).

Figure 10 Case 1: Simulation of the standard laboratory Kaiser Effect test on the calibrated clumped specimen under uniaxial stress condition. Stage 1: axial loading; Stage 2: axial unloading; and Stage 3: axial reloading (all stages under an unconfined condition).

Figure 11 Case 2: Investigation of memory effects on the calibrated clumped specimen under biaxial stress condition; gray curve represents lateral stress $\left(\sigma_{l}\right)$, and black curve represents axial stress $\left(\sigma_{a}\right)$. Stage 1: lateral unloading; Stage 2: axial unloading; and Stage 3: axial reloading under unconfined condition.

Figure 12 Case 3: Simulation of the Kaiser Effect test under triaxial stress condition. Gray curve represents lateral stress $\left(\sigma_{1}\right)$, and black curve represents axial stress $\left(\sigma_{\mathrm{a}}\right)$. The lower chart presents a zoomed-in view. Stage 1: axial loading under a confined condition; Stage 2: axial unloading under a confined condition; Stage 3: lateral unloading; Stage 4: axial unloading under an unconfined condition; and Stage 5: axial reloading under an unconfined condition.

Figure 13 Case 4: Cumulative number of cracks versus stress in the simulated core drilled from the borehole parallel to the $\sigma_{1}$. Gray curve represents lateral stress $\left(\sigma_{l}\right.$ or $\left.\sigma_{3}\right)$, and black curve represents axial stress $\left(\sigma_{a}\right.$ or $\left.\sigma_{1}\right)$. Stage 1: axial unloading under a confined condition; Stage 2: 
lateral unloading under constant axial load; Stage 3: axial unloading under an unconfined condition; Stage 4: axial reloading under an unconfined condition.

Figure 14 Case 5: Cumulative number of cracks versus stress in the simulated core drilled from the borehole parallel to the $\sigma_{3}$ direction. Gray curve represents lateral stress ( $\sigma_{l}$ or $\sigma_{1}$ in this case), and black curve represents axial stress $\left(\sigma_{a}\right.$ or $\sigma_{3}$ in this case). Stage 1: axial unloading under a confined condition; Stage 2: lateral unloading; Stage 3: axial reloading under an unconfined condition after rotation of $\sigma_{1}$.

Figure 15 a) $\sigma_{1}$ contours around the excavated tunnel; b) close-up view of Fig. 15a showing the locations of monitoring points.

Figure 16 a) locations of monitoring points relative to the failed zone and the locations of microseismic events (modified from Martin 1997, with permission from Dr. Martin); b) stress paths of seven monitoring points during tunnel excavation along with laboratory crack initiation stress threshold; c) damage (dark gray lines represent bond failures) in the clump model after the application of $2 \mathrm{D}$ stress paths.

pg. 36 

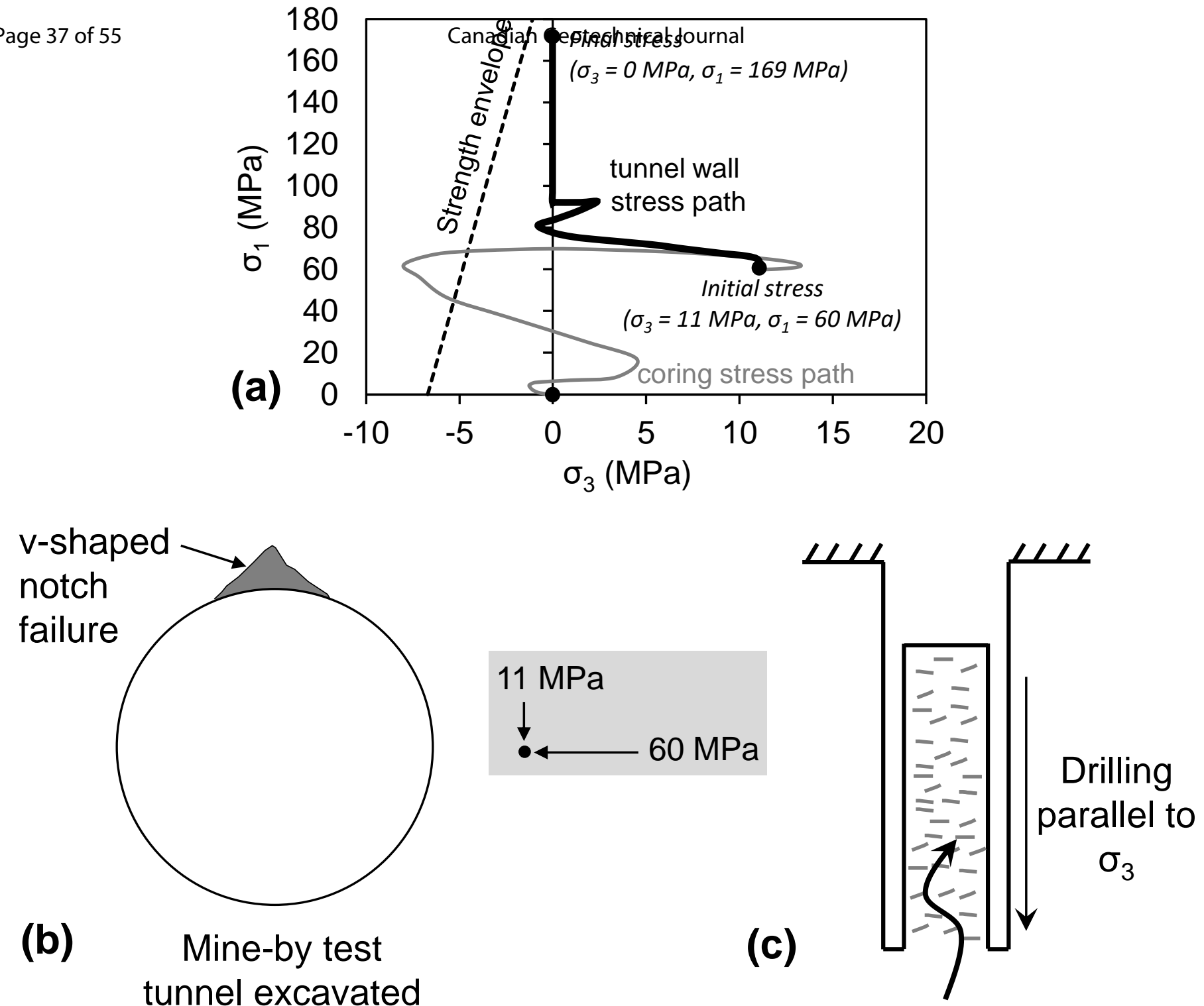

(b)

Mine-by test tunnel excavated parallel to $\sigma_{2}$

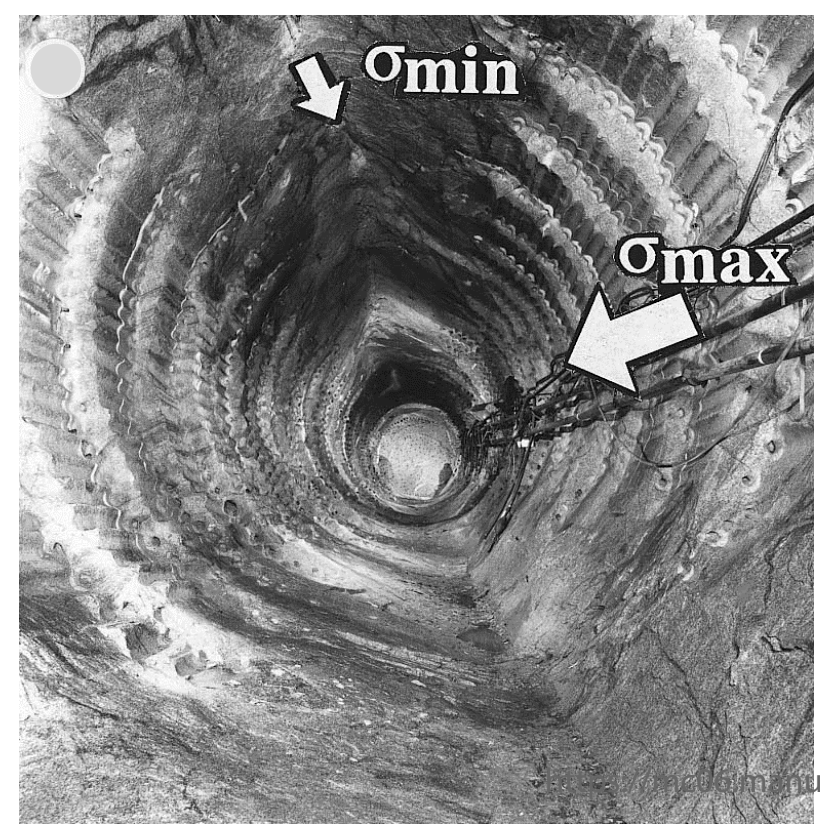

drilling-induced core damage/disking

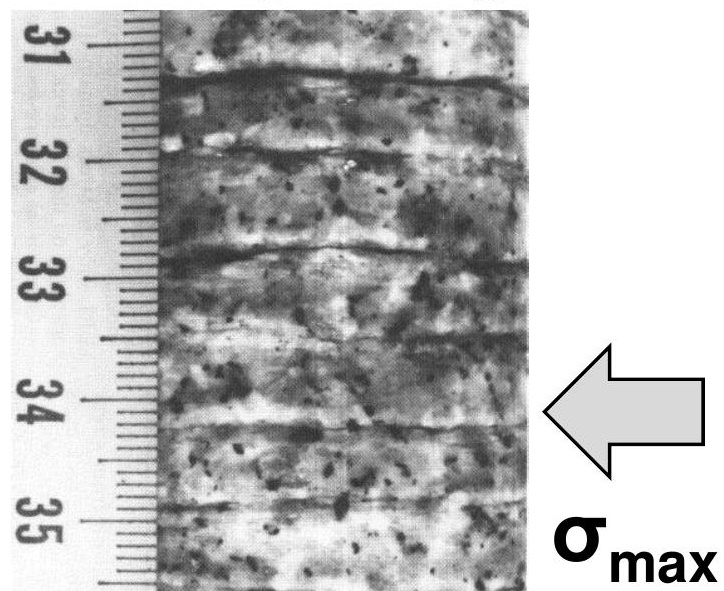



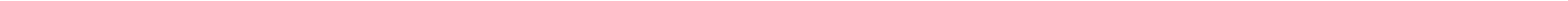


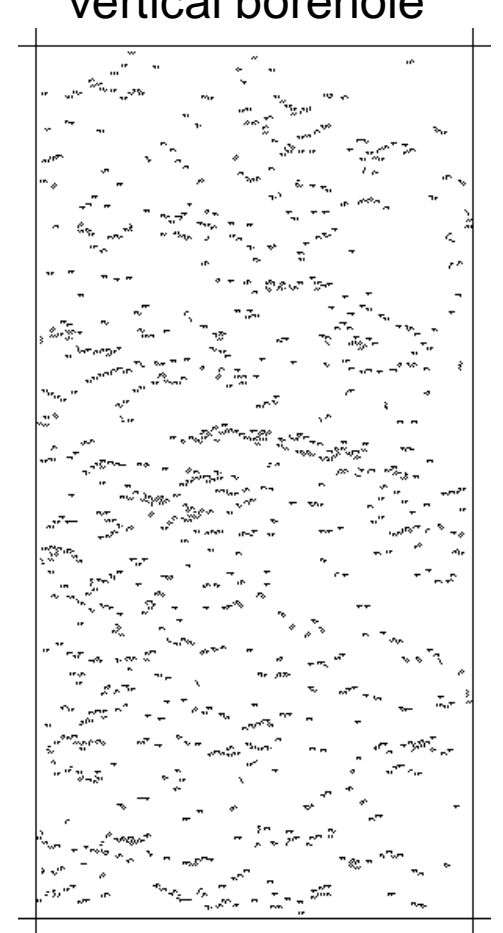

(a)

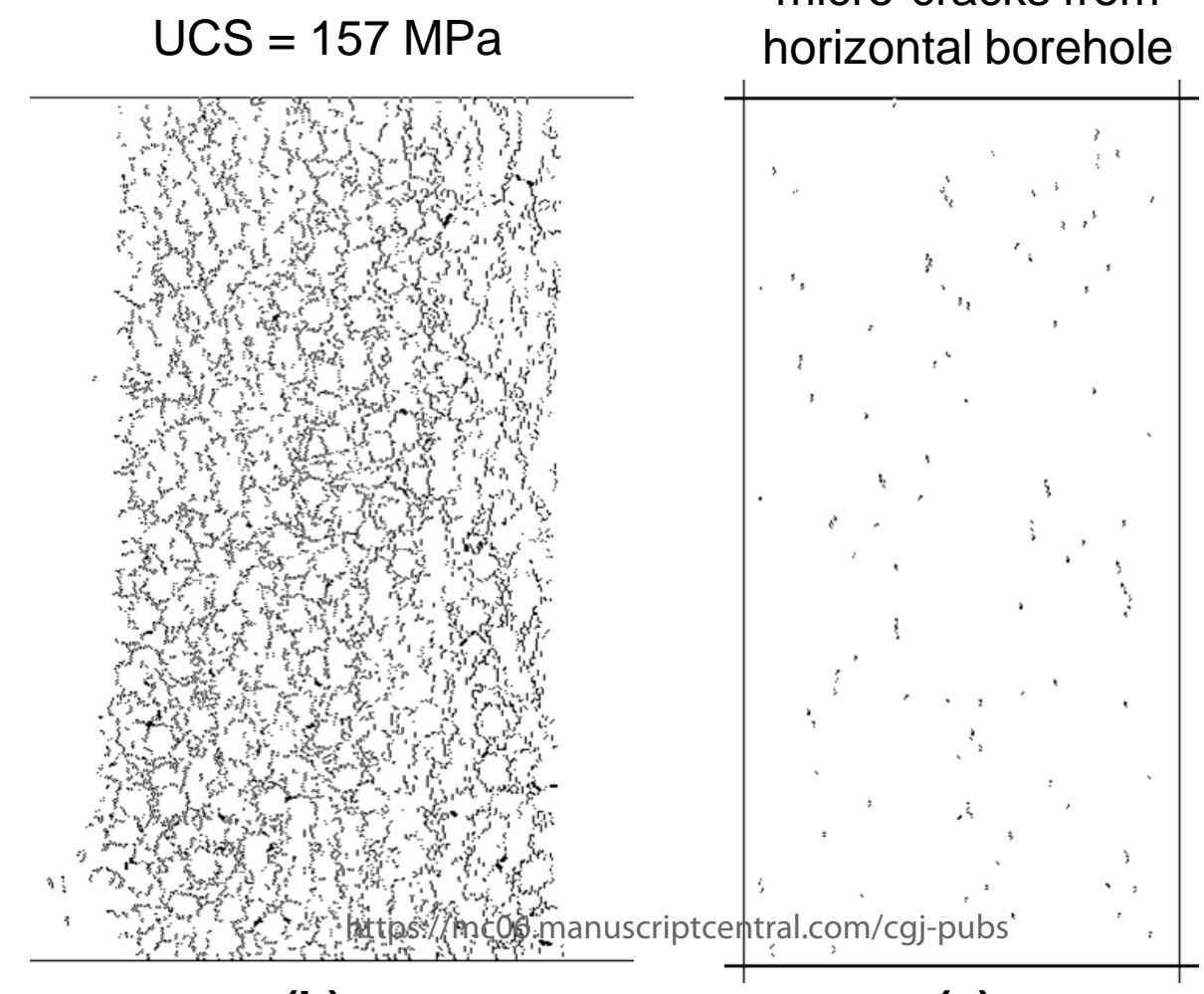

(b) (c)

$$
\mathrm{UCS}=212 \mathrm{MPa}
$$

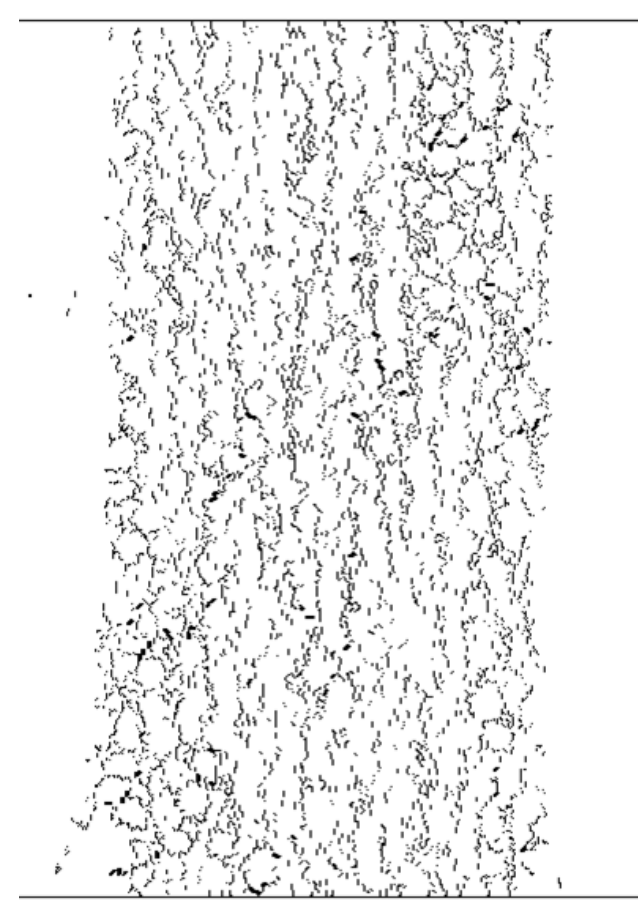

(d) 

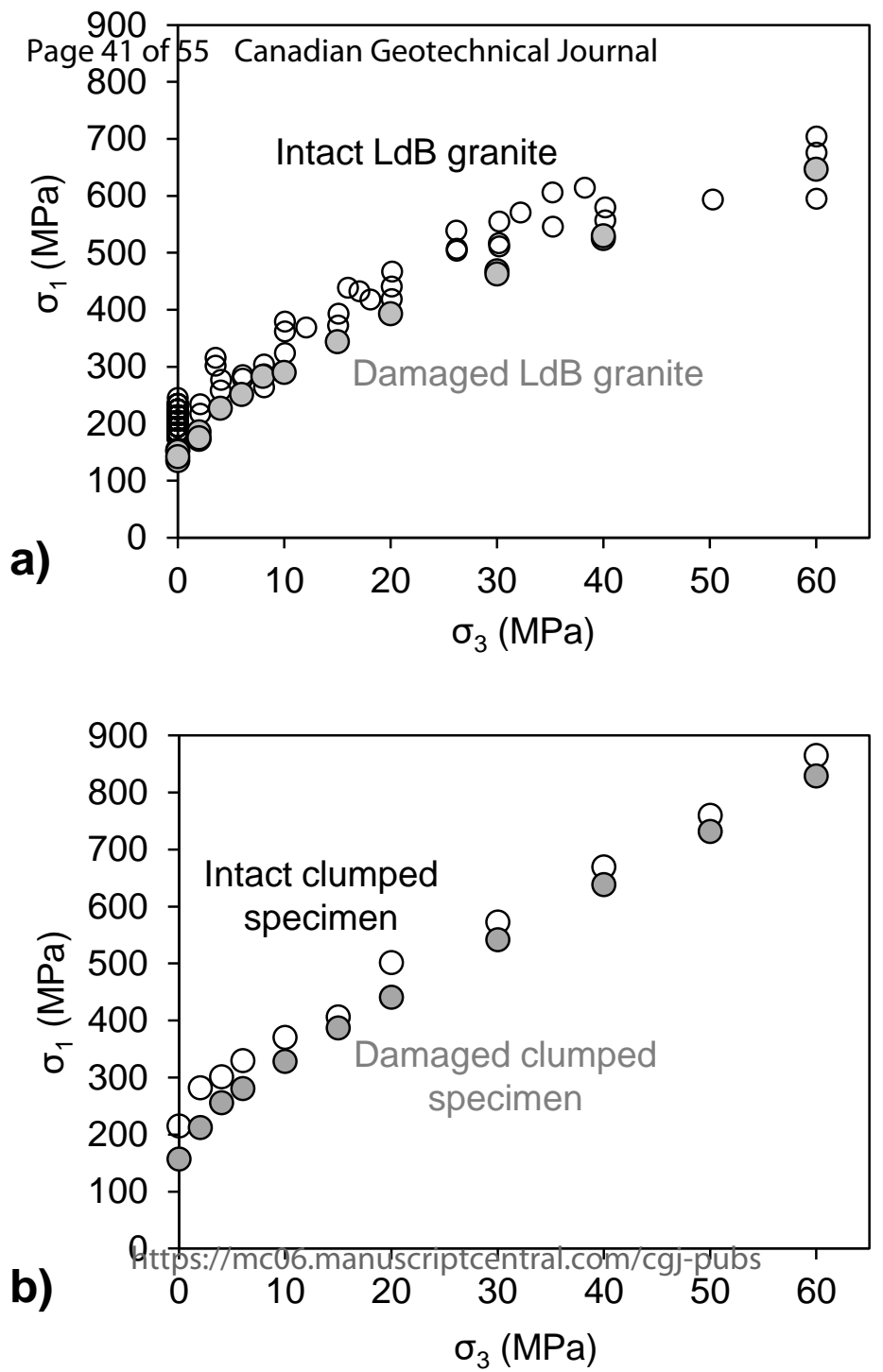


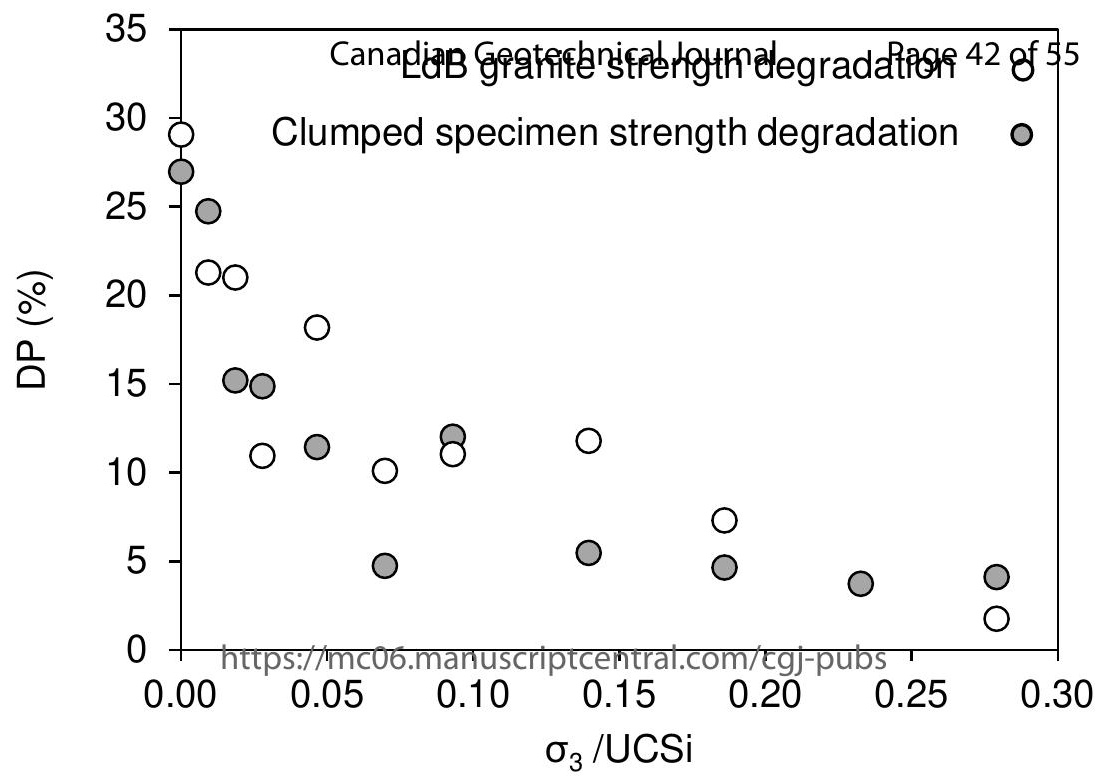




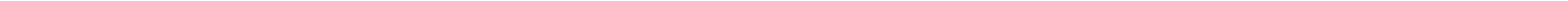


$\sigma_{H}$

个

Canadian Geotechnical Journal Page 44 of 55

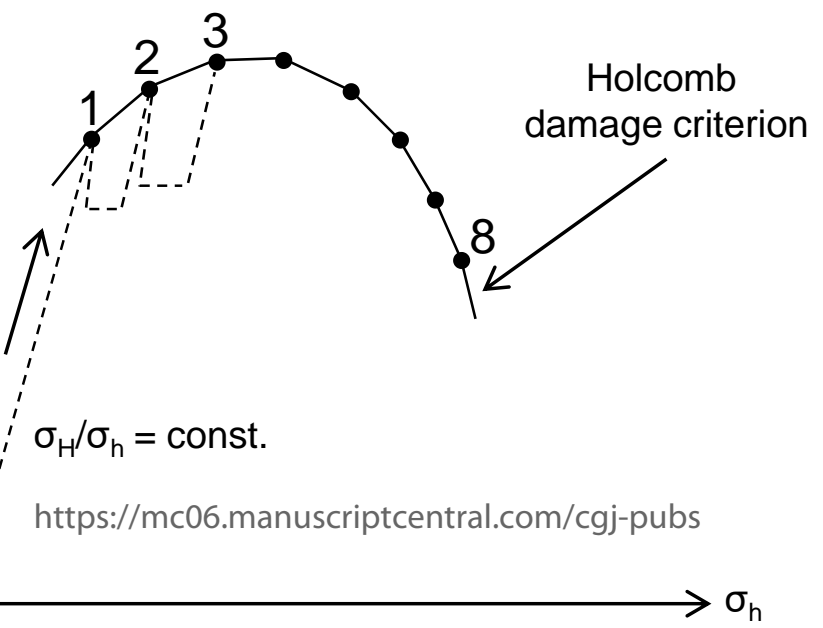




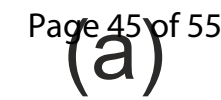

\section{Axial stress}

$\sigma_{a}$

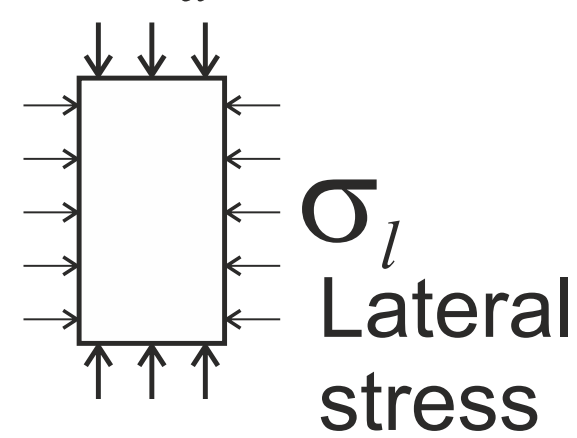

Initial stress

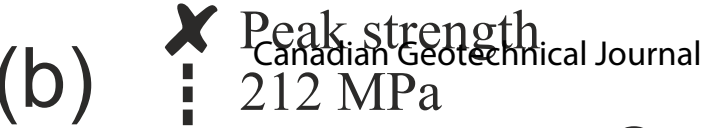

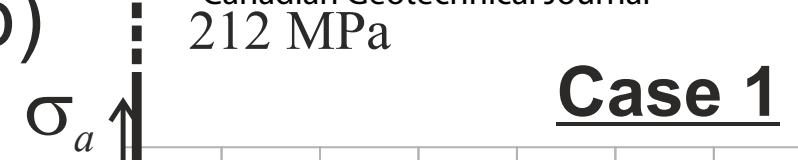

$\mathrm{MPa}$

(d) $X$ Peak strength

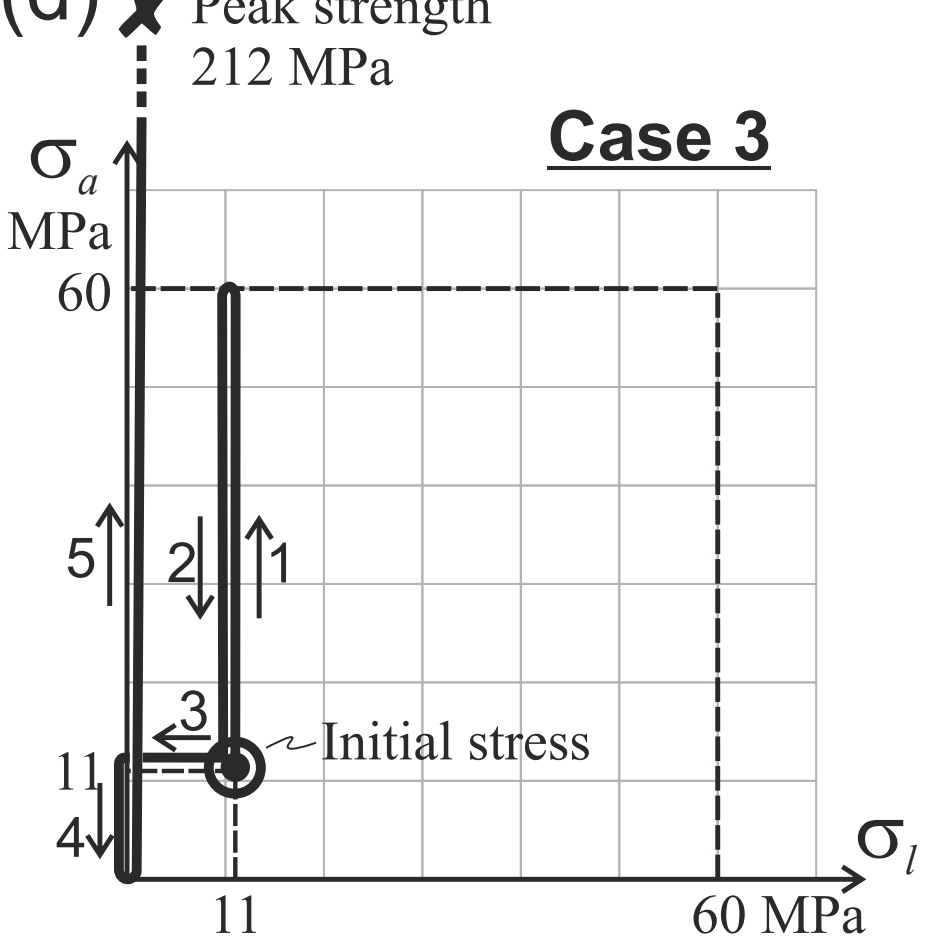

(e)

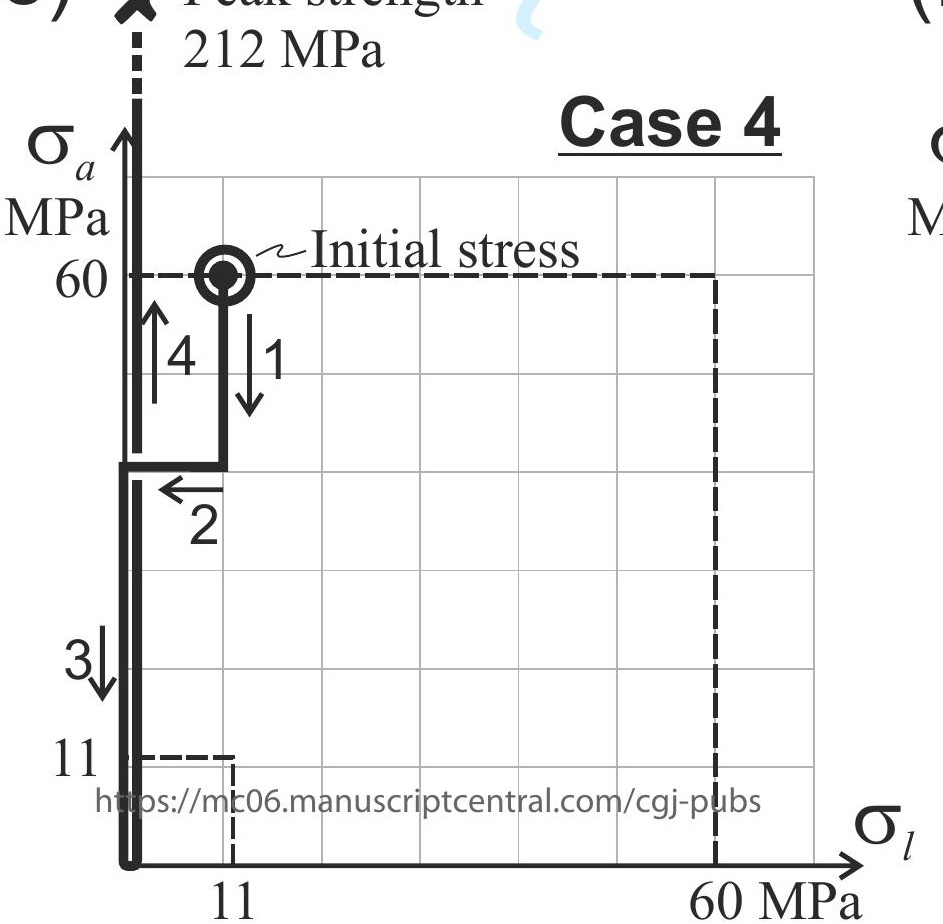

(c) $X$ Peak strength

(C) $212 \mathrm{MPa}$

$\sigma_{a} \uparrow$

60
2

3

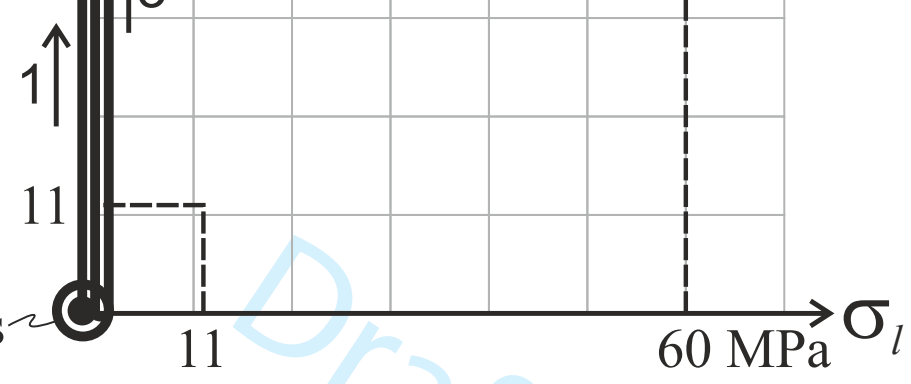

(f)

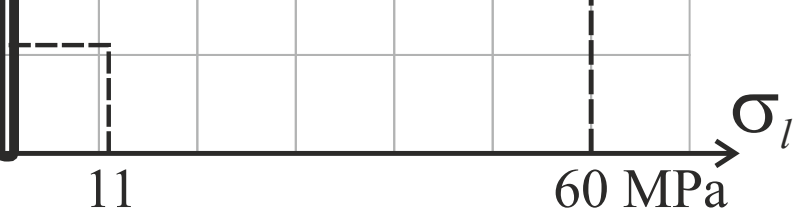

60

$\leftarrow$

11

3

$2 \downarrow$

Case 2

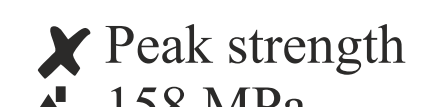

$\sigma_{a} \uparrow 158 \mathrm{MPa}$

Case 5
60

11

3 


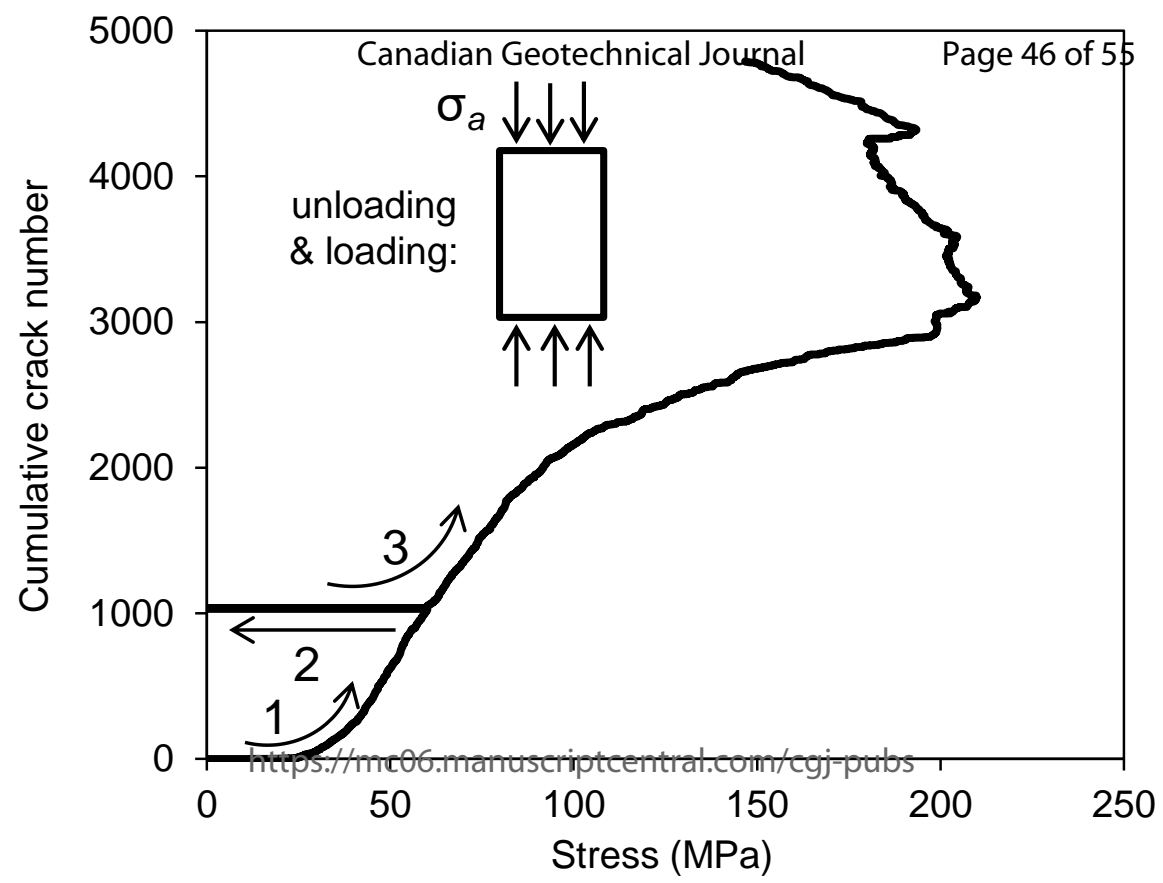




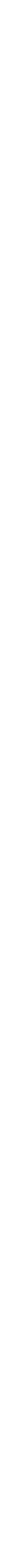




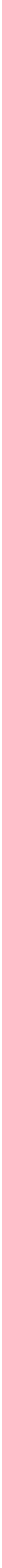

\section{0}




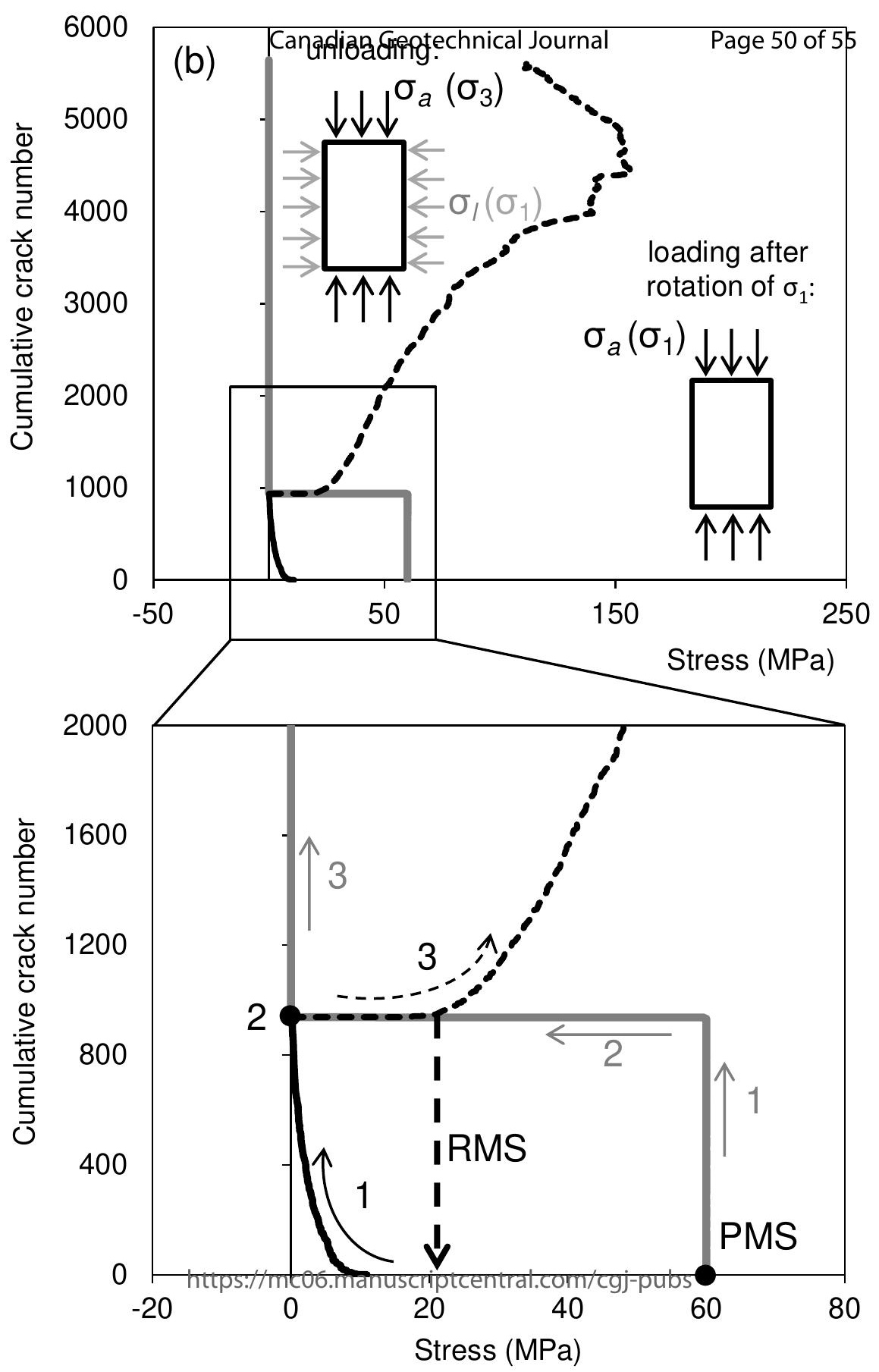




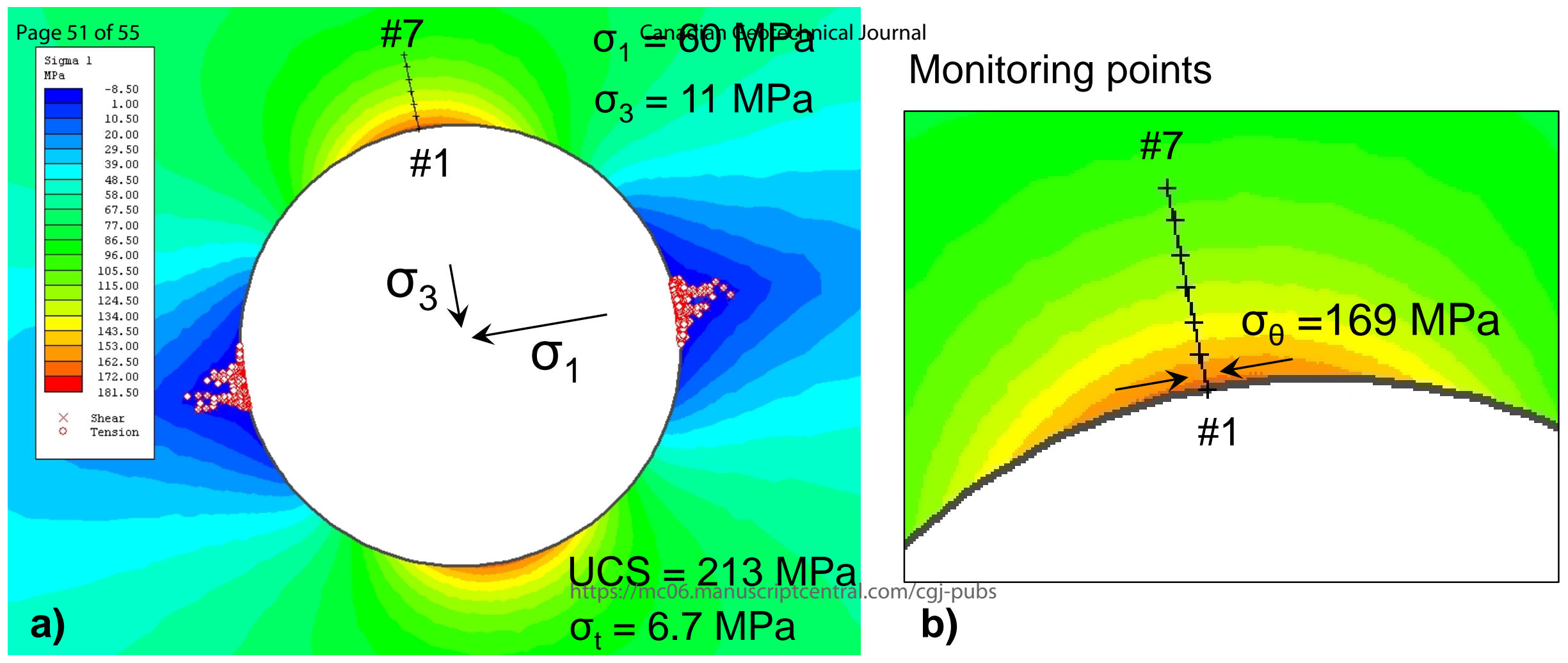




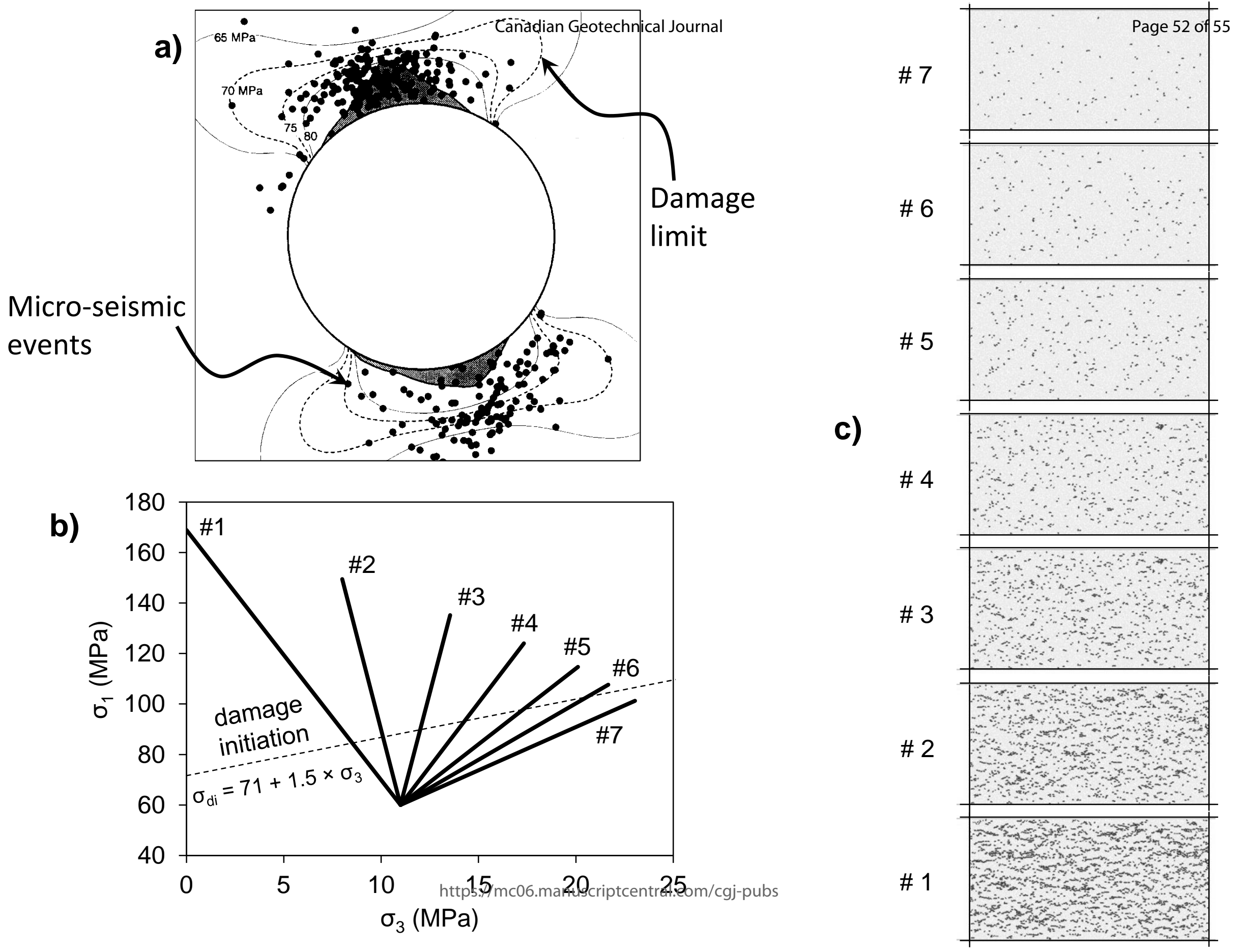




\section{TABLES}

Table 1 Micro-properties of the calibrated clumped particle model (after Bahrani et al. 2015, with permission from Elsevier).

\begin{tabular}{lcc}
\hline \multicolumn{1}{c}{ Parameter } & Symbols & Values \\
\hline Minimum particle radius & $R_{\min }$ & $0.2 \mathrm{~mm}$ \\
Ratio of maximum to minimum particle radius & $R_{\max } / R_{\min }$ & 1.5 \\
Contact and parallel bond stiffness ratios (normal to shear) & $k_{n} / k_{s}$ and $\bar{k}^{n} / \bar{k}^{s}$ & 2.5 \\
Contact bond moduli & $E_{c}$ & $15 \mathrm{GPa}$ \\
Parallel bond moduli & $\bar{E}_{c}$ & $18 \mathrm{GPa}$ \\
Particle friction coefficient & $\mu$ & 0.3 \\
Parallel bond radius multiplier & $\bar{\lambda}$ & 1 \\
Parallel bond normal strength & $\bar{\sigma}_{n}$ & $12 \pm 1.2 \mathrm{MPa}$ \\
Parallel bond shear strength & $\bar{\sigma}_{s}$ & $155 \mathrm{MPa}$ \\
Clump radius & $R_{c l}$ & $1 \pm 0.2 \mathrm{~mm}$ \\
\hline
\end{tabular}

Table 2 Comparison of laboratory and numerical simulation test results after calibration on undamaged (intact) and damaged LdB granite.

\begin{tabular}{ccc}
\hline Parameters & LdB granite & Clumped specimen \\
\hline Undamaged UCS $(\mathrm{MPa})$ & $213 \pm 20$ & $212 \pm 13$ \\
Undamaged E (GPa) & $65 \pm 5$ & $65 \pm 3$ \\
Damaged UCS (MPa) & $157 \pm 18$ & $158 \pm 18$ \\
Damaged E (GPa) & $52 \pm 2$ & $48 \pm 3$ \\
\hline
\end{tabular}

Table 3 Lateral and axial stress magnitudes (in MPa) at the end of each loading/unloading stage for the study of the 'stress memory' in Cases 1 to 5 (the peak strength of the clumped specimen is marked with *).

\begin{tabular}{ccccccccccccc}
\hline & \multicolumn{2}{c}{ Initial stress } & \multicolumn{2}{c}{ Stage 1 } & \multicolumn{2}{c}{ Stage 2 } & \multicolumn{2}{c}{ Stage 3 } & \multicolumn{2}{c}{ Stage 4 } & \multicolumn{2}{c}{ Stage 5 } \\
\cline { 2 - 12 } Case \# & $\sigma_{l}$ & $\sigma_{a}$ & $\sigma_{l}$ & $\sigma_{a}$ & $\sigma_{l}$ & $\sigma_{a}$ & $\sigma_{l}$ & $\sigma_{a}$ & $\sigma_{l}$ & $\sigma_{a}$ & $\sigma_{l}$ & $\sigma_{a}$ \\
\hline 1 & 0 & 0 & 0 & 60 & 0 & 0 & 0 & $212^{*}$ & & & \\
2 & 11 & 60 & 0 & 60 & 0 & 0 & 0 & $212^{*}$ & & & & \\
3 & 11 & 11 & 11 & 60 & 11 & 11 & 0 & 11 & 0 & 0 & 0 & $212^{*}$ \\
4 & 11 & 60 & 11 & 40 & 0 & 40 & 0 & 0 & 0 & $212^{*}$ &
\end{tabular}

pg. 1 
$\begin{array}{lllllllll}5 & 60 & 11 & 60 & 0 & 0 & 0 & 0 & 158^{*}\end{array}$

Table 4 Summary of the attempts to the simulation of the v-shaped notch formation at the AECL URL mine-by tunnel experiment, and estimated rock mass strength.

\begin{tabular}{lccc}
\hline \multicolumn{1}{c}{ Model description } & $\begin{array}{c}\text { Back-calculated rock } \\
\text { mass UCS }\end{array}$ & $\begin{array}{c}\text { Depth of notch } \\
\text { failure }\end{array}$ & Reference \\
\hline $\begin{array}{l}\text { Continuum, elastic: simulated } \\
\text { with monotonic removal of } \\
\text { failed material }\end{array}$ & $114 \mathrm{MPa}$ & Overestimated & Martin (1997) \\
$\begin{array}{l}\text { Continuum, elastic } \\
\text { Continuum, elastic-perfectly } \\
\text { plastic }\end{array}$ & $128 \mathrm{MPa}$ & underestimated & $\begin{array}{c}\text { Hajiabdolmajid et } \\
\text { al. (2002) }\end{array}$ \\
$\begin{array}{l}\text { Continuum, elastic brittle } \\
\text { underestimated }\end{array}$ & $\begin{array}{c}\text { Hajiabdolmajid et } \\
\text { al. (2002) }\end{array}$ \\
$\begin{array}{l}\text { Continuum, strain-dependent } \\
\text { CWFS }\end{array}$ & $128 \mathrm{MPa}$ & underestimated & $\begin{array}{c}\text { Hajiabdolmajid et } \\
\text { al. (2002) }\end{array}$ \\
$\begin{array}{l}\text { Discontinuum: Bonded } \\
\text { Particle Model (BPM) }\end{array}$ & $128 \mathrm{MPa}$ & Captured & $\begin{array}{c}\text { Hajiabdolmajid et } \\
\text { al. (2002) }\end{array}$ \\
$\begin{array}{l}\text { Discontinuum: Dynamic } \\
\text { BPM (low damping) }\end{array}$ & $120 \mathrm{MPa}(\mathrm{estimated})$ & Captured & $\begin{array}{c}\text { Potyondy and } \\
\text { Cundall (2004) }\end{array}$ \\
$\begin{array}{l}\text { Continuum, strain- } \\
\text { independent CWFS material }\end{array}$ & $<120 \mathrm{MPa}$ (estimated) & Captured & $\begin{array}{c}\text { Hazzard and Young } \\
\text { (2004) }\end{array}$ \\
$\begin{array}{l}\text { Discontinuum: UDEC-GBM, } \\
\text { strain-dependent CWFS } \\
\text { model for bonds between } \\
\text { blocks }\end{array}$ & $100 \mathrm{MPa}$ & Captured & Diederichs (2007) \\
$\begin{array}{l}\text { Continuum, strain- } \\
\text { independent CWFS: } \\
\text { simulated with tunnel } \\
\text { boundary irregularities }\end{array}$ & $205 \mathrm{MPa}$ & Slightly \\
$\begin{array}{l}\text { Finite element-discrete } \\
\text { element (FDEM) }\end{array}$ & & underestimated & Shin (2010) \\
\hline
\end{tabular}

pg. 2 
Table 5 Properties of $\mathbf{R S}^{2}$ model of mine-by-tunnel experiment.

\begin{tabular}{lcc}
\hline Parameter & Symbols & Values \\
\hline Unconfined Compressive Strength & $U C S$ & $213 \mathrm{MPa}$ \\
Tensile Strength & $\sigma_{t}$ & $6.7 \mathrm{MPa}$ \\
Poisson's ratio & $v$ & 0.3 \\
Elastic Modulus & $E$ & $65 \mathrm{GPa}$ \\
\hline
\end{tabular}

pg. 3 